\title{
Mitochondrial DNA Sequence and Lack of Response to Anoxia in the Annual Killifish Austrofundulus limnaeus
}

\author{
Josiah T. Wagner*, Florisela Herrejon Chavez and Jason E. Podrabsky \\ Department of Biology, Center for Life in Extreme Environments, Portland State University, Portland, OR, USA
}

The annual killifish Austrofundulus limnaeus inhabits ephemeral ponds in regions of Venezuela, South America. Permanent populations of $A$. limnaeus are maintained by production of stress-tolerant embryos that are able to persist in the desiccated sediment. Previous work has demonstrated that $A$. limnaeus have a remarkable ability to tolerate extended periods of anoxia and desiccating conditions. After considering temperature, A. limnaeus embryos have the highest known tolerance to anoxia when compared to any other vertebrate yet studied. Oxygen is completely essential for the process of oxidative phosphorylation by mitochondria, the intracellular organelle responsible for

OPEN ACCESS

Edited by:

Paolo Bernardi,

University of Padua, Italy

Reviewed by:

Michael A. Menze,

Eastern Illinois University, USA Joanna Kelley,

Washington State University, USA

*Correspondence: Josiah T. Wagner josw@pdx.edu

Specialty section: This article was submitted to Mitochondrial Research, a section of the journal

Frontiers in Physiology

Received: 18 June 2016 Accepted: 17 August 2016 Published: 31 August 2016

Citation:

Wagner JT, Herrejon Chavez F and Podrabsky JE (2016) Mitochondrial DNA Sequence and Lack of Response to Anoxia in the Annual Killifish

Austrofundulus limnaeus.

Front. Physiol. 7:379.

doi: 10.3389/fphys.2016.00379 the majority of adenosine triphosphate production. Thus, understanding the unique properties of $A$. limnaeus mitochondria is of great interest. In this work, we describe the first complete mitochondrial genome ( $m$ tgenome) sequence of a single adult $A$. limnaeus individual and compare both coding and non-coding regions to several other closely related fish mtgenomes. Mitochondrial features were predicted using MitoAnnotator and polyadenylation sites were predicted using RNAseq mapping. To estimate the responsiveness of $A$. limnaeus mitochondria to anoxia treatment, we measure relative mitochondrial DNA copy number and total citrate synthase activity in both relatively anoxia-tolerant and anoxia-sensitive embryonic stages. Our cross-species comparative approach identifies unique features of ND1,ND5, ND6, and ATPase-6 that may facilitate the unique phenotype of $A$. limnaeus embryos. Additionally, we do not find evidence for mitochondrial degradation or biogenesis during anoxia/reoxygenation treatment in A. limnaeus embryos, suggesting that anoxia-tolerant mitochondria do not respond to anoxia in a manner similar to anoxia-sensitive mitochondria.

Keywords: annual killifish, anoxia, mitochondria, citrate synthase, embryo, mitochondrial genome

\section{INTRODUCTION}

Mitochondria are intracellular organelles that play a central and essential role in basic eukaryotic cell biology by regulating metabolism, the cell cycle, and cell survival or death. The organelle is best known for synthesizing the majority of cellular adenosine triphosphate (ATP) by oxidative phosphorylation (OXPHOS). Synthesis of ATP through mitochondrial OXPHOS is completely dependent on a constant availability of oxygen as the terminal electron acceptor. In most vertebrates, prolonged exposure to anoxia typically causes mitochondrial dysfunction and 
eventually cell death by necrosis or apoptosis (Johnston et al., 2001; Verma et al., 2002; Levraut et al., 2003). However, some aquatic vertebrates are able to tolerate extensive periods of anoxia. Of these anoxia-tolerant vertebrates, embryos of the annual killifish Austrofundulus limnaeus (Meyers) have a tolerance of anoxia that is approximately two orders of magnitude greater than any other vertebrate species yet examined (Podrabsky et al., 2007, 2012b). Development in A. limnaeus has a predictable and unique phenotype that has been wellcharacterized. Thus, it is an ideal model organism for studying endogenous mechanisms that may facilitate extreme stress tolerance.

A. limnaeus (Family Rivulidae, Order Cyprinodontiformes) is commonly found in ephemeral habitats of the Maracaibo basin of Venezuela (Podrabsky et al., 1998; Hrbek et al., 2005). Due to seasonal fluctuations in water and oxygen availability, embryos of A. limnaeus embryos likely experience hypoxic or anoxic conditions as a regular part of their embryonic development (Podrabsky et al., 1998, 2015). In preparation for the seasonal desiccation of their habitat, $A$. limnaeus embryos enter into a state of developmental arrest and deep metabolic depression known as diapause. Diapause may occur at 3 distinct stages of development in annual killifish embryos, termed diapause I, II, and III (Wourms, 1972a,b,c). Although rare or absent in our lab stock, diapause I (DI) can occur early in development after completion of epiboly but prior to the formation of the embryonic axis (Wourms, 1972c). Diapause II (DII) occurs in the long-somite embryo approximately midway through development, just prior to the major phases of organogenesis, and appears to be the most stress-resistant diapause stage (Wourms, 1972a,b; Podrabsky et al., 2001, 2007, 2015). Finally, embryos may arrest as a late prehatching embryo in diapause III (DIII) rather than immediately hatching (Wourms, 1972a).

Anoxia tolerance peaks in A. limnaeus approximately midway through development during DII; this tolerance is retained for the first 4-6 days of post-diapause II (PDII) development and is then subsequently lost by the time embryos enter DIII (Podrabsky et al., 2007, 2012b). The mechanisms by which $A$. limnaeus embryos are able to tolerate anoxia are not completely known. However, previous work has suggested that during diapause, a combination of reduced ATP consumption through depressed protein synthesis, extremely low levels of OXPHOS activity, and depressed heart rate likely all contribute to the anoxia tolerant phenotype (Podrabsky and Hand, 1999, 2000; Duerr and Podrabsky, 2010). If exposed to anoxia during active development, embryos enter into a reversible state of quiescence and within hours of exposure experience a dramatic drop in ATP levels (Podrabsky et al., 2007, 2012a). Prolonged anoxia and acute deceases in ATP are typically followed by mitochondrialmediated cell death by apoptosis in other vertebrates, yet $A$. limnaeus embryos do not appear to follow the same trajectory

Abbreviations: ANOVA, analysis of variance; ATP, adenosine triphosphate; CS, citrate synthase; CSB, conserved sequence-block; DI, diapause I; DII, diapause II; DIII, diapause III; dpd, days post-diapause II; EtOH, ethanol; ML, maximum likelihood; mtDNA, mitochondrial DNA; mtgenome, mitochondrial genome; OXPHOS, oxidative phosphorylation; PDII, post-diapause II; qPCR, quantitative PCR; ROS, reactive oxygen species; SNP, single-nucleotide polymorphism; WS, Wourms' stage.
(Hand and Menze, 2008; Podrabsky et al., 2012a; Meller and Podrabsky, 2013). These studies suggest that A. limnaeus embryos have an atypical response to anoxia that likely involves unique mitochondrial physiology.

The process of OXPHOS is inherently complicated, requiring coordination between nuclear and mitochondrial proteins. Changes in mitochondrial DNA (mtDNA) sequence and copy number can have profound effects on mitochondrial protein function and expression. These changes can often have effects on mitochondrial physiology and subsequently affect the ability of an organism to cope with oxygen stress (Bratic and Larsson, 2013; Kowald and Kirkwood, 2014). Therefore, understanding how the A. limnaeus mitochondrial genome (mtgenome) may differ from less stress-tolerant species, and the phylogenetic relationship to other species, may provide insight into vertebrate mitochondrial evolution under the unique and intense selection pressures imposed by life in an ephemeral aquatic habitat. Additionally, little is known about the regulation of A. limnaeus embryonic mitochondrial biomass during anoxia, specifically whether or not mitochondrial genomes are stabilized or degraded. Previous work has suggested that in anoxia- and hypoxia-sensitive mammalian models, exposure of cells to long-term hypoxic conditions can result in mitochondrial autophagy (mitophagy) while acute anoxia followed by reoxygenation appears to result in mitochondrial biogenesis (Yin et al., 2008; Zhang et al., 2008; Youle and Van Der Bliek, 2012). As a part of these previous studies, measurement of mitochondrial:genomic DNA ratios and/or total citrate synthase (CS) activity were used to give an indication of mitochondrial degradation or biogenesis during normal and low oxygen conditions. We apply a similar strategy to explore the responsiveness of A. limnaeus embryonic mitochondria to sublethal anoxia/reoxygenation by measuring relative mtDNA content using quantitative PCR (qPCR) and total CS activity in post-diapause II embryos.

This work describes the first complete mitochondrial genome sequence of A. limnaeus (Strain: Quisiro) as assembled from a single adult male. We also use RNAseq mapping to infer post-transcriptional polyadenylation of primary mitochondrial transcripts. We discuss the unique features of the A. limnaeus mtgenome annotation when compared to several other species from the Order Cyprinodontiformes. To determine potential shifts in mitochondrial physiology, we measure relative mtDNA content and total CS activity following anoxia/reoxygenation in both relatively anoxia-tolerant [Wourms' stage (WS) 36, 4 days post-diapause II (dpd), $\mathrm{LD}_{50}$ anoxia $65=$ days] and anoxiasensitive (WS 40, $12 \mathrm{dpd}, \mathrm{LD}_{50}$ anoxia $=6$ days; WS 42, $22 \mathrm{dpd}$, $\mathrm{LD}_{50}$ anoxia $=12.1 \mathrm{~h}$ ) embryos (Podrabsky et al., 2007). Potential implications for understanding the role of mitochondria in the anoxia tolerance of $A$. limnaeus are discussed.

\section{MATERIALS AND METHODS}

\section{Husbandry of Adults and Maintenance of Embryos}

Adult A. limnaeus and their embryos were cared for as previously described by Podrabsky (1999) and in accordance with an 
approved Portland State University Institutional Animal Care and Use Committee protocol (PSU protocol \#33). Briefly, mating pairs were allowed access to spawning trays containing $1-2 \mathrm{~cm}$ of $500 \mu \mathrm{m}$ diameter soda-lime glass beads (30/40 mesh glass bead blasting media, Kramer Industries, Inc., Piscataway, NJ, USA) for $2 \mathrm{~h}$. Embryos were separated from the glass beads by straining through a $1.5 \mathrm{~mm}$ mesh and were collected using a wide-mouthed plastic pipette. Unfertilized eggs were discarded. For the first $3 \mathrm{~d}$ of development, embryos were kept in embryo medium formulated to mimic the ionic composition of their native ponds ( $10 \mathrm{mmol} \mathrm{l}^{-1} \mathrm{NaCl}, 2.14 \mathrm{mmol} \mathrm{l}^{-1} \mathrm{MgCl}_{2}, 0.8 \mathrm{mmol} \mathrm{l}^{-1} \mathrm{CaCl}_{2}$, $0.14 \mathrm{mmol} \mathrm{l}^{-1} \mathrm{KCl}, 0.0013 \mathrm{mmol}^{-1} \mathrm{MgSO}_{4}$ ) containing $0.0001 \%$ methylene blue to suppress fungal growth (Podrabsky et al., 1998; Podrabsky, 1999). At 4 days post-fertilization, embryos were treated with two $5 \mathrm{~min}$ washes of a $0.01 \%$ solution of sodium hypochlorite (Clorox Bleach) in embryo medium and transferred to embryo medium containing $10 \mathrm{mg} \mathrm{l}^{-1}$ gentamicin sulfate (Podrabsky, 1999). Embryo medium was changed daily and embryos were incubated at $25^{\circ} \mathrm{C}$ in darkness until sorting.

\section{Total Genomic DNA Extraction of Adult Tissues DNA Extraction of Adult Tissues for Illumina Sequencing}

The tissue used for DNA sequencing was derived from a single male $A$. limnaeus at 3 months post-hatch. The laboratory stock this individual was sampled from has been maintained since 1995 and originated from near Quisiro, Maracaibo basin, Venezuela. The fish was euthanized by immersion in an ice bath for $\sim 5$ min followed by cervical transection. Liver, white muscle (with skin and scales removed), and brain tissue were removed and transferred to DNA extraction buffer $[10 \mathrm{mmol}$ $1^{-1}$ Tris- $\mathrm{HCl} \mathrm{pH}=8.0,100 \mathrm{mmol} \mathrm{l}^{-1}$ EDTA, 0.5\% SDS, $200 \mu \mathrm{g} \mathrm{ml}^{-1}$ Proteinase $\mathrm{K}$ (Thermo Scientific, Waltham, MA, USA, \#EO0491)] at a ratio of $1 \mathrm{mg}$ tissue per $10 \mu \mathrm{l}$ buffer. Tissues were gently homogenized using a Teflon pestle in $1.5 \mathrm{ml}$ microcentrifuge tubes and incubated for $3 \mathrm{~h}$ at $50^{\circ} \mathrm{C}$ with agitation every 20-30 min. DNA was extracted by briefly vortexing the homogenates with 1 vol phenol (equilibrated with $10 \mathrm{mmol} \mathrm{l}^{-1}$ Tris- $\mathrm{HCl}, \mathrm{pH}=8.0,1 \mathrm{mmol} \mathrm{l}^{-1}$ EDTA) followed by centrifugation at $5000 \times \mathrm{g}$ for $10 \mathrm{~min}$ at $4^{\circ} \mathrm{C}$. The aqueous phases were collected using a wide-bore pipette and extracted with phenol as described above. Following the second phenol extraction, the aqueous phases containing the DNA were extracted a third time by gentle mixing with 1 volume of chloroform:phenol (1:1) followed by centrifugation at $5000 \times$ $\mathrm{g}$ for $10 \mathrm{~min}$ at $4^{\circ} \mathrm{C}$. The aqueous phase was collected and the DNA precipitated by the addition of $\mathrm{NaCl}$ (final concentration of $200 \mathrm{mmol} \mathrm{l}^{-1}$ ) and 2 volumes of $100 \%$ ethanol (EtOH) followed by mixing by gentle inversion. The DNA was pelleted by centrifugation at $16,000 \times g$ for $10 \mathrm{~min}$ at $4^{\circ} \mathrm{C}$. The DNA pellet was washed twice with $1 \mathrm{ml} 70 \% \mathrm{EtOH}$. After each wash the DNA was pelleted by centrifugation at $16,000 \times \mathrm{g}$ for $5 \mathrm{~min}$ at $4{ }^{\circ} \mathrm{C}$. The air-dried DNA pellet was resuspended in $500 \mu \mathrm{l}$ of RNAse buffer ( $10 \mathrm{mmol} \mathrm{l}^{-1}$ Tris- $\mathrm{HCl}, \mathrm{pH}=8,5 \mathrm{mmol} \mathrm{l}^{-1}$ EDTA) with $100 \mu \mathrm{g} \mathrm{ml}^{-1}$ DNAse-free RNAse A (Thermo Scientific \#EN0531) and incubated at $37^{\circ} \mathrm{C}$ for $45 \mathrm{~min}$ with occasional tube inversion. The samples were extracted twice more as described above with chloroform:phenol (1:1) followed by precipitation using $0.1 \mathrm{vol}$ of $3 \mathrm{~mol} \mathrm{l}^{-1}$ sodium acetate $\mathrm{pH}=5.2$, and 2 vol of $100 \%$ EtOH. The DNA was pelleted by centrifugation at $16,000 \times \mathrm{g}$ for $10 \mathrm{~min}$ at $4^{\circ} \mathrm{C}$ and the pellet was washed twice with $1 \mathrm{ml} 70 \%$ EtOH as described above. The DNA pellets were dried briefly at room temperature and resuspended in $100 \mu \mathrm{l}$ of buffer EB $\left(10 \mathrm{mmol} \mathrm{l}^{-1}\right.$ Tris- $\mathrm{HCl} \mathrm{pH}=8.5$, Qiagen, Hilden, Germany, $\# 19086)$ at $37^{\circ} \mathrm{C}$ with occasional agitation until pellets dissolved completely.

\section{DNA Quantification and Quality Assessment}

Total genomic DNA concentrations and $\mathrm{A}_{260} / \mathrm{A}_{280}$ ratios were determined using the Infinite M200 Pro plate reader equipped with a NanoQuant plate (Tecan, San Jose, CA, USA) using $2 \mu \mathrm{L}$ of sample and default software settings (i-control software, Tecan). We considered $\mathrm{A}_{260} / \mathrm{A}_{280}$ ratios between 1.9 and 2.1 to be of acceptable DNA purity. DNA integrity was determined by $1 \%$ agarose gel electrophoresis of $1 \mu \mathrm{g}$ of total DNA and observation of high-molecular weight DNA above $20 \mathrm{~kb}$.

\section{DNA Sequencing and Read Quality Control} Illumina Sequencing

DNA sequencing libraries from the mixed tissue sample were prepared and sequenced at the University of Oregon High Throughput DNA Sequencing and Genomics facility. Purified DNA was sonicated to an average size of $170 \mathrm{bp}$ and was prepared for sequencing using the Nextera library prep kit (Illumina, San Diego, CA, USA). Fragment libraries were sequenced on the Illumina Hi-Seq 2500 platform with 101 bp paired-end reads.

\section{Sanger Sequencing}

Polymerase chain reaction (PCR) was used to amplify specific regions of the mitochondrial genome. PCR products were generated using total DNA from adult liver as the DNA template. PCR reactions ( $50 \mu \mathrm{l}$ total volume) consisted of $50 \mathrm{ng}$ total DNA, 10 pmol of forward and reverse primers (Table S1, Integrated DNA Technologies, Coralville, IA, USA), $0.25 \mathrm{U}$ Taq polymerase (New England BioLabs, Ipswich, MA, USA \#M0267L), in 1X ThermoPol buffer (New England BioLabs \# M0267L). The reactions were heated for an initial $5 \mathrm{~min}$ at $95^{\circ} \mathrm{C}$ followed by 40 cycles of: $20 \mathrm{~s}$ at $95^{\circ} \mathrm{C}, 20 \mathrm{~s}$ at $60^{\circ} \mathrm{C}$, and $5 \mathrm{~min}$ at $68^{\circ} \mathrm{C}$. A single final elongation step of $10 \mathrm{~min}$ at $68^{\circ} \mathrm{C}$ followed the initial 40 cycles. PCR products were resolved via $1 \%$ agarose electrophoresis and product size was estimated by comparison to a DNA ladder (GeneRuler $1 \mathrm{~kb}$ Plus, Thermo Scientific \#SM0312) using GelAnalyser (http://www.sequentix. de/). PCR products were then excised and cloned into the pGEM-T vector or sequenced directly (Table S2). Plasmids were heat-shock transformed into E. coli JM109 high-efficiency cells (Promega \#L2001, Madison, WI, USA) as recommended by the manufacturer. Plasmids were purified using the Qiagen Miniprep kit and Sanger sequenced at Oregon Health and Science University using the primers indicated in Table S2. 


\section{Read Quality Control}

Adapters were removed from Illumina reads using Trimmomatic version 0.36 (Bolger et al., 2014) and the included Illumina adapter list. Error-correction was performed using the Allpaths error correction module (Gnerre et al., 2011). Of the total read pool that passed adapter trimming and error-correction, 100 million forward and reverse reads were randomly chosen for mtgenome assembly (Table S3). Sanger reads were trimmed of vector contamination using the UniVec tool in the Geneious 6.1.8 suite (Biomatters, Auckland, New Zealand) and bases with a greater than $5 \%$ chance of error were trimmed (Kearse et al., 2012).

\section{Assembly and Annotation of the $A$. limnaeus Mitochondrial Genome}

The A. limnaeus mitochondrial genome was assembled using mitochondrial baiting and iterative mapping (MitoBIM) software on the default settings (Hahn et al., 2013). Input sequence consisted of 100 million post-trim forward reads (SRA \#SRR2006331, Table S3). These reads were also a part of the read pool used to assemble the A. limnaeus nuclear genome (GenBank assembly accession: GCA_001266775.1). A short DNA sequence of $A$. limnaeus cytochrome $c$ oxidase I (NCBI accession AF002589.1) was used to seed the initial baiting of mitochondrial reads. Geneious software (version 8.1.7) was used to generate and visualize subsequent alignments (Kearse et al., 2012). Sanger contigs from sequenced clones were assembled de novo and mapped to the mtgenome using Geneious (Table S2). Forward and reverse reads were mapped using the Geneious algorithm to determine coverage and assembly quality (max gap size 15 bp; minimum $\geq 90 \%$ overlap identity; multiple best matches randomly mapped; paired reads must match nearby; word length $=10$ ). Single nucleotide polymorphisms (SNPs) were called using the Geneious Variant Caller with a minimum frequency of $10 \%$ and more stringent mapping settings $(\geq 99.9 \%$ read mapping confidence; max gap size $15 \mathrm{bp} ; \geq 90 \%$ identity; multiple best matches matched to none; paired reads must match nearby; word length $=10$ ).

The resulting $A$. limnaeus mitochondrial genome was annotated using the MitoAnnotator pipeline (Iwasaki et al., 2013). Conserved sequence blocks (CSBs) were identified from consensus sequences derived from previously identified sequences (Broughton et al., 2001; Lee et al., 2001). The MITOS webserver was used to fold tRNAs into predicted cloverleaf structures (Bernt et al., 2013). To identify the A. limnaeus tRNA-Ser, the tRNA-Ser from $N$. furzeri was mapped to the A. limneus reference mtgenome using Geneious (50\% identity minimum setting). Repetitive motif identification and clustering were obtained using RepFind (Betley et al., 2002).

\section{Mitochondrial Genome Investigations Phylogenetic Analysis}

Complete mitochondrial genomes from several other Cyprinodontiform fishes were retrieved from the MitoFish database for comparative analysis (Table 1; Iwasaki et al., 2013). Mitochondrial genes in comparator species were identified using the MitoAnnotator pipeline as done with A. limnaeus. Individual coding genes without stops, rRNAs, and tRNAs were aligned using the MUSCLE alignment tool as part of the Geneious suite ver. 8.1.7 (Edgar, 2004; Kearse et al., 2012). Third codon positions were removed from alignments to avoid saturation bias (Kumazawa and Nishida, 1993). Poorly aligned regions were trimmed using the GBLOCKS webserver (http://molevol. cmima.csic.es/castresana/Gblocks_server.html) with default settings (Castresana, 2000). JModelTest 2 was used to estimate the best model of nucleotide substitution on the concatenated alignment (Darriba et al., 2012). The final alignment contained 10,875 nucleotide positions and phylogenetic relationships were inferred using RAxML-HPC 7.7.2 using settings for GTR + I $+\mathrm{G}, 1000$ bootstrap replications, and partitioning by first and second codon positions, rRNAs, and tRNAs (Stamatakis, 2006). RAxML was run using the rapid-hill climbing algorithm that also returned the best-resulting maximum likelihood (ML) tree in a single step. Oryzias latipes (Order Beloniformes) was specified as an outgroup.

\section{Codon Usage and Nucleotide Composition}

Codon usage tables and nucleotide position composition ratios of coding genes were obtained using CAIcal (Puigbò et al., 2008).

\section{RNAseq Mapping and Polyadenylatyion Calling}

Illumina RNAseq reads derived from a pooled sample of 24 somite embryos reared at $30^{\circ} \mathrm{C}$ (SRA \#SRR2032241) were used to identify mRNA expression of the A. limnaeus mtgenome in addition to polyadenylation signals. Sequenced reads were filtered on quality scores and trimmed for the presence of adapter sequences using Trimmomatic (Bolger et al., 2014) with the following settings: ILLUMINACLIP:2:30:7:1:true, SLIDINGWINDOW:5:15, LEADING:20, TRAILING:20, and MINLEN: 25. Following trimming, RNAseq reads had an average length of $97 \mathrm{bp}$, standard deviation of $11 \mathrm{bp}$, and a read length range of 25-100 bp. Filtered and trimmed reads were initially mapped to the annotated A. limnaeus mtgenome using Geneious software (version 8.1.7; $\max$ gap size $=5$, $\max$ gaps per read $10 \%$, $\geq 80 \%$ identity, map multiple best matches randomly) to estimate overall coverage of the mtgenome by RNAseq. To predict polyadenylation sites, slightly more stringent mapping settings were used that omitted reads with multiple best matches ( $\geq 99.9 \%$ read mapping confidence, no gaps, $\geq 80 \%$ identity, word length $=10)$. Similar to previous studies, we set a threshold requiring three or more non-template adenine nucleotides at a variant frequency of $>4 \%$ to call a polyadenylated region at a putative $3^{\prime}$ transcript end (Marková et al., 2015).

\section{RNA and DNA Secondary Structure Predictions}

The A. limnaeus mitochondrial origin of light-strand replication (Ori-L) and tRNA-Ser putative secondary structures were predicted using Geneious software ver 8.1.7 with default DNA energy mode settings at $25^{\circ} \mathrm{C}$ (Mathews et al., 2004 model).

\section{Membrane Protein Topology Predictions}

The TOPCONS webserver was used for consensus predictions of A. limnaeus mitochondrial peptide membrane topology with default settings (Tsirigos et al., 2015). Secondary structure predictions were performed using PSIPRED v3.3 with default 
TABLE 1 | List of fish mitochondrial genomes used in this work.

\begin{tabular}{|c|c|c|c|c|c|c|c|c|}
\hline Species & Family & Annual & $\begin{array}{c}\text { Genbank } \\
\text { accession }\end{array}$ & $\begin{array}{l}\text { Total length } \\
\text { (bp) }\end{array}$ & $\begin{array}{c}\text { D-loop } \\
\text { length (bp) }^{a}\end{array}$ & Total GC\% ${ }^{\mathbf{b}}$ & Coding GC $\%$ c & References \\
\hline $\begin{array}{l}\text { Austrofundulus } \\
\text { limnaeus }\end{array}$ & Rivulidae & Yes & KX371089 & 21,039 & $2284(4647)$ & 37.3 & 39.1 & This work \\
\hline $\begin{array}{l}\text { Nothobranchius } \\
\text { furzeri }\end{array}$ & Nothobranchiidae & Yes & NC_011814.1 & 19,527 & 2091 (3273) & 38.6 & 38.4 & Hartmann et al., 2011 \\
\hline $\begin{array}{l}\text { Austrolebias } \\
\text { charrua }\end{array}$ & Rivulidae & Yes & NC_028510.1 & 17,271 & 1349 & 36.8 & 37.4 & Gutiérrez et al., 2015 \\
\hline $\begin{array}{l}\text { Kryptolebias } \\
\text { marmoratus }\end{array}$ & Rivulidae & No & NC_003290 & 17,329 & 887 (1682) & 43.3 & 44 & Lee et al., 2001 \\
\hline $\begin{array}{l}\text { Aplocheilus } \\
\text { panchax }\end{array}$ & Aplocheilidae & No & NC_011176 & 16,519 & 860 & 42.7 & 42.8 & Setiamarga et al., 2008 \\
\hline $\begin{array}{l}\text { Cyprinodon } \\
\text { rubrofluviatilis }\end{array}$ & Cyprinodontidae & No & NC_009125 & 16,501 & 831 & 46.5 & 47.3 & Crowl et al., unpublished \\
\hline $\begin{array}{l}\text { Fundulus } \\
\text { heteroclitus }\end{array}$ & Fundulidae & No & NC_012312 & 16,526 & 865 & 39.7 & 38.9 & Whitehead, 2009 \\
\hline $\begin{array}{l}\text { Fundulus } \\
\text { diaphanus }\end{array}$ & Fundulidae & No & NC_012361 & 16,531 & 867 & 38.9 & 38 & Whitehead, 2009 \\
\hline $\begin{array}{l}\text { Fundulus } \\
\text { grandis }\end{array}$ & Fundulidae & No & NC_012377 & 16,524 & 866 & 40.4 & 39.9 & Whitehead, 2009 \\
\hline $\begin{array}{l}\text { Fundulus } \\
\text { olivaceus }\end{array}$ & Fundulidae & No & NC_011380 & 16,509 & 853 & 42.2 & 42.3 & Whitehead, 2009 \\
\hline $\begin{array}{l}\text { Gambusia } \\
\text { affinis }\end{array}$ & Poeciliidae & No & NC_004388 & 16,614 & 858 & 44.9 & 45.5 & Miya et al., 2003 \\
\hline $\begin{array}{l}\text { Jordanella } \\
\text { floridae }\end{array}$ & Cyprinodontidae & No & NC_011387 & 16,177 & - & 45 & 45.2 & Setiamarga et al., 2008 \\
\hline $\begin{array}{l}\text { Xenotoca } \\
\text { eiseni }\end{array}$ & Goodeidae & No & NC_011381 & 16,735 & 862 & 41.5 & 41.6 & Setiamarga et al., 2008 \\
\hline $\begin{array}{l}\text { Xiphophorus } \\
\text { hellerii }\end{array}$ & Poeciliidae & No & NC_013089 & 16,635 & 857 & 47.8 & 49 & Setiamarga et al., 2008 \\
\hline $\begin{array}{l}\text { Xiphophorus } \\
\text { maculatus }\end{array}$ & Poeciliidae & No & NC_011379 & 16,646 & 859 & 46.8 & 47.8 & Setiamarga et al., 2008 \\
\hline Oryzias latipes & Adrianichthyidae & No & NC_004387 & 16,714 & 1073 & 44.5 & 45 & Miya et al., 2003 \\
\hline
\end{tabular}

All species are from the Order Cyprinodontiformes except for O. latipes, which is Order Beloniformes.

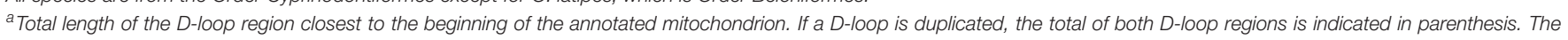
mitochondrial sequence of $\mathrm{J}$. floridae is incomplete and is missing part of the $D$-loop region.

${ }^{b}$ Total GC\% of the entire mtgenome for each species.

${ }^{c}$ Total GC\% of coding genes, not including stop codons.

settings on the PSIPRED Protein Sequence Analysis Workbench webserver (Jones, 1999; Buchan et al., 2013). Bovine (Bos taurus) mitochondrial peptide sequences for ND1 (P03887), ND5 (Q85BD6), and ND6 (P03924) were downloaded from the UniProt database and used for comparison to A. limnaeus homologs (UniProt, 2015).

\section{qPCR Analysis of Normoxic and Anoxia-Treated A. limnaeus Embryos Anoxia Treatment}

Embryos were exposed to anoxia as previously described (Podrabsky et al., 2012a). To obtain PDII embryos, A. limnaeus embryos were staged at DII and diapause was experimentally terminated by placing dormant embryos in a $33^{\circ} \mathrm{C}$ incubator illuminated with $24 \mathrm{~h}$ illumination for 2 days before being returned to $25^{\circ} \mathrm{C}$ in the dark. PDII embryos were staged to one of three developmental stages using a dissecting scope: WS 36 (early organogenesis, $4 \mathrm{dpd}$ ), WS 40 (full overgrowth, $12 \mathrm{dpd}$ ), or WS 42 (early prehatching, $22 \mathrm{dpd}$; Wourms, 1972a). Prior to anoxia treatment, embryos were collected in petri dishes $(100 \times 15 \mathrm{~mm}$ plastic dishes) and excess embryo medium was removed using a pipette. Embryos were transferred into a Bactron III anaerobic chamber (Sheldon Manufacturing, Cornelius, OR) and rinsed three times with embryo medium that was previously purged for 30 min with $\mathrm{N}_{2}$ gas and allowed to equilibrate inside the anoxic chamber overnight. Anoxic conditions were maintained through the use of an anaerobic gas mixture $\left(5 \% \mathrm{H}_{2}, 5 \% \mathrm{CO}_{2}\right.$, balance $\mathrm{N}_{2}$ ) and a palladium catalyst for the duration of anoxia exposure. Embryos at WS 36, 40, and 42 were sampled in normoxia $(t=0)$, after $24 \mathrm{~h}$ of anoxia, and after $24 \mathrm{~h}$ of aerobic recovery from anoxia ( 9 embryos per replicate). Unexposed normoxic embryos at 24 and $48 \mathrm{~h}$ were also sampled for parallel comparison. Diapause II embryos were sampled only in normoxia. Embryos were incubated at $25^{\circ} \mathrm{C}$ for the duration of the experiment in all treatments. Prior to sampling, embryos were collected onto 
a nylon mesh screen (100 $\mathrm{m}$ mesh) and blotted dry using Kimwipes before being transferred into $1.5 \mathrm{ml}$ microcentrifuge tubes and flash-frozen in liquid $\mathrm{N}_{2}$. Frozen embryos were stored at $-80^{\circ} \mathrm{C}$ until DNA extraction.

\section{Total Genomic DNA Extraction of Embryos}

Embryonic DNA was extracted using the DNeasy Blood and Tissue Kit (Qiagen, \#69581). Embryos were homogenized on ice in microcentrifuge tubes using a Teflon pestle with $400 \mu \mathrm{l}$ of kit provided lysis buffer ATL and $2 \mathrm{mg} \mathrm{ml}^{-1}$ of Proteinase $\mathrm{K}$ (Thermo Scientific, \#EO0491). Samples were incubated at $56^{\circ} \mathrm{C}$ for $1 \mathrm{~h}$ and then centrifuged for $5 \mathrm{~min}$ at $300 \times \mathrm{g}$ at $4^{\circ} \mathrm{C}$ to pellet insoluble debris. Supernatants were transferred into new microcentrifuge tubes and $400 \mu \mathrm{l}$ of buffer AL was added. Samples were vortexed briefly and incubated at $56^{\circ} \mathrm{C}$ for $10 \mathrm{~min}$. Each sample was then mixed with $400 \mu \mathrm{l}$ of $100 \% \mathrm{EtOH}$, vortexed briefly, and applied to the DNeasy silica columns according to manufacturer instructions. After washing columns according to manufacturer's instructions, DNA was eluted in $100 \mu \mathrm{l}$ of buffer AE. Quality and quantity of DNA was assessed as described above for the adult tissues.

\section{mtDNA and gDNA qPCR Assays}

Primers for qPCR were designed using default settings in the IDT PrimerQuest tool (http://www.idtdna.com/Primerquest/) with the mitochondrial gene NADH dehydrogenase 4 (ND4) or nuclear insulin-like growth factor-1 receptor (IGFR1, NCBI Reference Sequence: XM_014003519.1) genes as inputs (Table S4). The amplification specificity of each gene/primer set was verified by cloning amplicons generated from A. limnaeus embryo tissues into the pGEM-T Easy Vector (Promega, Madison, WI, \#A1360), transformation into JM109 High-efficiency cells (Promega, \#L2001), and Sanger DNA sequencing the plasmid inserts as previously described (Wagner and Podrabsky, 2015). Purified plasmids with verified PCR inserts for either ND4 or IGFR1 were used as standards for qPCR assays. qPCR reactions $(20 \mu l$ total volume) were set up in triplicate using SsoAdvanced Universal SYBR Green Supermix (Bio-Rad, Hercules, CA, USA, \#172-5270) and consisted of $25 \mathrm{ng}$ total DNA, $10 \mu \mathrm{l}$ of $2 \mathrm{X}$ SsoFast Probes Supermix, and $500 \mathrm{nmol}^{-1}$ of forward and reverse primers. Assays were set up in clear 96-well semi-skirted PCR plates (Hard-Shell High-Profile PCR plates, Bio-Rad, \#HSS-9601) with optical flat caps (Bio-Rad, \#TCS-0803). All qPCR reactions were carried out in the Stratagene Mx3005P thermocycler (Agilent Technologies, Santa Clara, CA). Standard curves were generated using a serial 1:10 dilution of amplicon-specific plasmid copies (1 ng $-1 \mathrm{e}^{-7}$ ng for ND4 and $1 \mathrm{e}^{-1}-1 \mathrm{e}^{-7}$ for IGFR1). Reactions were initially heated at $95^{\circ} \mathrm{C}$ for $5 \mathrm{~min}$ to activate the DNA polymerase and subsequently thermocycled for 35 cycles by denaturation at $95^{\circ} \mathrm{C}$ for $30 \mathrm{~s}$ and annealing/elongation at $60^{\circ} \mathrm{C}$ for $30 \mathrm{~s}$. Fluorescence readings (excitation $492 \mathrm{~nm}$, emission $516 \mathrm{~nm}$ ) were taken at the end of each elongation step. Quantification cycle $\left(\mathrm{C}_{\mathrm{q}}\right)$ thresholds were set automatically in Stratagene MxPro software (v.4.10, 2007, Agilent Technologies) using adaptive baseline, moving average, and amplification-based threshold settings. Although rarely necessary, thresholds were manually adjusted to improve standard curve best-fit regressions. Reaction efficiencies of ND4 or IGFR1 ( $\mathrm{E}_{\text {gene }}$ ) were estimated using the standard curve slopes such that $\mathrm{E}_{\text {gene }}=10^{(-1 / \text { slope })}$ (Pfaffl, 2001). Assays were validated by visualizing $\mathrm{qPCR}$ end products via gel electrophoresis in addition to observation of a single melting dissociation curve.

\section{Citrate Synthase Activity Assays}

Embryos were treated, sampled, weighed, and flash-frozen for CS activity assays as described for the anoxia qPCR assays, except replicates consisted of 7 pooled individuals for all stages but DII, which consisted of 9 individuals per replicate. Embryos previously frozen in $1.5 \mathrm{ml}$ microcentrifuge tubes were diluted 1:10 (w:v) in ice-cold $10 \mathrm{mmol} \mathrm{l}^{-1}$ HEPES $\left(\mathrm{pH} 7.5\right.$ at $25^{\circ} \mathrm{C}$ ) and homogenized on ice using a Teflon pestle. Crude homogenates were centrifuged at $300 \times g$ for $5 \mathrm{~min}$ at $4^{\circ} \mathrm{C}$ to pellet insoluble debris. Supernatants were transferred to new tubes and stored at $-80^{\circ} \mathrm{C}$ until assays were performed. Total citrate synthase enzymatic activity was determined spectrophotometrically at $25^{\circ} \mathrm{C}$ (PharmaSpec 1700 , Shimadzu, Kyoto, Japan) by measurement of absorbance at $412 \mathrm{~nm}$ as previously described (Torres and Somero, 1988; Chennault and Podrabsky, 2010). Assays were performed with 1 to 2 technical replicates for each sample. Total CS activity was measured in $1 \mathrm{ml} 50 \mathrm{mmol}^{-1}$ imidazole ( $\mathrm{pH} 7.7$ at $25^{\circ} \mathrm{C}$ ) buffer containing $15 \mathrm{mmol} \mathrm{l}^{-1} \mathrm{MgCl}_{2}, 0.1 \mathrm{mmol} \mathrm{l} \mathrm{l}^{-1} \mathrm{DTNB}$, and $0.1 \mathrm{mmol}^{-1}$ acetyl coenzyme A. Background activity for each sample was determined by addition of $10 \mu \mathrm{l}$ embryo homogenate and measurement of change in absorbance for $2 \mathrm{~min}$. Assays were then initiated by addition of $25 \mu \mathrm{l}$ of $0.7 \mathrm{mmol}$ $1^{-1}$ oxaloacetic acid (in imidazole buffer as described above) and change in absorbance was recorded for $4 \mathrm{~min}$. Activity slopes were calculated by linear regression in GraphPad Prism (v5.0, La Jolla, CA, USA) using absorbance values for the last $60 \mathrm{~s}$ of the background activity and the first $60 \mathrm{~s}$ following addition of oxaloacetic acid. Final CS activity slopes were determined by subtraction of background activity from the total activity following addition of oxaloacetate to yield CS-specific activity. Activities are expressed in international units (IU, $\mu \mathrm{mol}$ oxaloacetate $\min ^{-1}$ embryo $^{-1}$ ).

\section{Statistical Analysis}

Statistical analysis for qPCR and CS activity data were performed using GraphPad Prism v5.0. Differences in relative copy number or CS activity were calculated using one-way Analysis of Variance (ANOVA) followed by Tukey's multiple comparison test (Tukey's MCT). Statistical significance was determined at $P<0.05$. Linear regression of normoxic data was also performed using GraphPad Prism v5.0. For qPCR experiments, fold differences in mtDNA (ND4) or gDNA (IGFR1) copy number in PDII embryos were calculated relative to DII samples using the efficiency corrected $\mathrm{ddC}_{\mathrm{q}}$ method (Relative fold difference of gene $=\mathrm{E}_{\text {gene }}^{\text {(CqDII-CqPDII) }}$ where $\mathrm{C}_{q} \mathrm{DII}$ is the $\mathrm{C}_{\mathrm{q}}$ of the DII sample and $\mathrm{C}_{\mathrm{q}} \mathrm{PDII}$ is the $\mathrm{C}_{q}$ of the PDII sample; Pfaffl, 2001). Prior to statistical analysis of qPCR data by one-way ANOVA, relative mtDNA copy number was normalized to relative gDNA copy number [Normalized ND4 fold difference $=($ Relative fold difference in ND4 $) /($ Relative fold change in IGFR1)] and $\log _{2}$ transformed. 


\section{RESULTS AND DISCUSSION}

\section{Sequence Analysis of the A. limnaeus Mitochondrial Genome \\ Coding Gene Composition and Gene Structures}

The complete $A$. limnaeus mitochondrial genome contains 21,039 bases, $37.3 \%$ GC content, and is circular. MitoAnnotator identified two rRNAs, 21 unique tRNAs, 13 protein-coding genes, and two D-loops (D-loop 1 and D-loop 2) separated by a partial 16S rRNA unit and duplicated tRNA-Leu2 sequence (Figure 1, Table 2). The initial assembly of the A. limnaeus mtgenome using only MitoBIM and Illumina reads incorrectly assembled the duplicated D-loop region, as discovered by post-assembly read mapping and identification of breakpoints characteristic of misassembly. Cloned PCR products amplified from around the D-loop region identified the correct sequence order (Figure 2). The correct sequence order was confirmed by mapping of Illumina reads from both forward and reverse libraries with a final average coverage of 9059X (range 1579X-19,520X). A total of $1,705,832$ reads mapped with $85 \%$ of bases mapping with quality $>$ Q20. The resulting mtgenome assembly has been deposited into NCBI Genbank (KX371089).

The protein-coding genes included $\mathrm{NADH}$-ubiquinone oxidoreductase (complex I) subunits 1, 2, 3, 4, 5, and 6 (ND1, ND2, ND3, ND4, ND5, and ND6), cytochrome $c$ oxidase subunits 1,2 , and 3 (COI, COII, COIII), cytochrome $b$ (Cytb), and $\mathrm{F}_{1} \mathrm{~F}_{o}$-ATP synthase subunits (ATPase-6 and ATPase-8). Identical to the mtgenomes of other species within the Order Cyprinodontiformes used in this study, most identified genes and RNAs were determined to be encoded on the heavy $(\mathrm{H}$, purine rich) strand, aside from the ND6 gene and eight tRNAs which are encoded on the light (L, pyrimidine rich) strand (Iwasaki et al., 2013). As expected, TOPCONS was able to predict transmembrane domains for all putative coding genes based on translated structure (Table 2).

The overall gene nucleotide composition of the A. limnaeus mtgenome is similar to other Cyprinodontiform fishes examined (Table 1). Also similar to the other Cyprinodontiformes, the $A$. limnaeus coding genes that are transcribed on the $\mathrm{H}$ strand are depleted of guanine at the third codon position (Figure S1A). This bias against guanine at the third codon positions is not as apparent in ND6 (Figure S1B), which is transcribed on the L strand. Overall, the A. limnaeus coding genes show negative skew for AT [skew: $(\mathrm{A}-\mathrm{T}) /(\mathrm{A}+\mathrm{T})$ ] and $\mathrm{GC}$ [skew: $(\mathrm{G}-\mathrm{C}) /(\mathrm{G}+\mathrm{C})$ ], indicating a bias toward the pyrimidines $\mathrm{T}$ and $\mathrm{C}$ in all coding genes except for ND6 (Figure S2). The top five most frequent codons for the aplocheloid fish are listed in Table S5. These five species share three of the top five most frequently used codons in their respective mtgenomes.

Five SNPs were identified at $10 \%$ frequency or higher, with four occurring in the $16 \mathrm{~S}$ rRNA and one predicted to cause a synonymous amino acid change in ND4L (Table 3). The four SNPs occurring in the $16 \mathrm{~S}$ rRNA appear to occur as a single haplotype, as suggested by nearly identical frequency of occurrence of the SNPs at this site, as well as simultaneous presence of all four SNPs in the reads that map to the region. The shared frequency between the 16S rRNA SNPs and the ND4L SNP indirectly suggest that there may be an alternative mitochondrial haplotype occurring at $\sim 25 \%$ in the read pool that contains the five identified SNPs.

\section{Cross-Species Sequence Divergence of Coding Genes}

Although the total length of the A. limnaeus mtgenome is larger than other species used in this study, the lengths of coding genes are comparable, with exceptions for ND1, ND5, ND6, and ATPase-6 (Figure 3). The A. limnaeus ND1 gene is shorter near the $5^{\prime}$ by 27 nucleotides (alignment positions 13-39) and also differs by having a "GTG" start codon rather than "ATG." ND5 is longer near the $5^{\prime}$ end by 33 nucleotides (alignment positions 7-39) and has an "ATA" start codon as opposed to the overall consensus of "ATG." ND6 is $5^{\prime}$ truncated by 54 nucleotides (alignment positions 1-54) and has a "GTG" start codon instead of "ATG." Finally, ATPase- 6 differs at both $5^{\prime}$ and 3 ' ends, with a small insertion of 6 nucleotides at the $5^{\prime}$ (alignments positions 510) and an extension of 34 nucleotides at the $3^{\prime}$ end compared to other species. NCBI BLASTx or BLASTn searches of the extended sequence in ATPase- 6 did not return significant results. These unique gene features do not have clear implications for the mitochondrial physiology of $A$. limnaeus, but the number of differences, and the clustering of the differences in complex I and $\mathrm{V}$ suggest the potential for functional significance.

Seven mitochondrial-encoded subunits form the hydrophobic core of complex I, which participates in essential functions such as forming a channel for ubiquinone to move out of the lipid bilayer and into the protein complex and proton transfer (Hirst, 2013). Importantly, the majority of ROS production from ETC activity is thought to occur in complex I (Stowe and Camara, 2009; Quinlan et al., 2012). PSIPRED secondary structure predictions of $A$. limnaeus ND1 and ND5 did not reveal major structural changes when compared to their bovine homologs. However, the first transmembrane helix (ND6TMH1) of A. limnaeus ND6 appears to be incomplete or absent when compared to bovine ND6 (Figure 4). Bovine ND6-TMH1 is believed to be closely associated with other transmembrane helices in ND6 and ND4L. Currently there are no other known instances of a vertebrate missing ND6-TMH1, but the possible functional relevance of these missing residues is unknown (Vinothkumar et al., 2014; Judy Hirst, pers. comm.).

Similar to the structural changes in ND6, the effect of the extended $\mathrm{N}$ - and C-termini of the ATPase- 6 gene when compared to other fish species is not immediately clear. ATPase6 comprises the a subunit of complex $\mathrm{V}$ (the $\mathrm{F}_{\mathrm{o}}$ subunit of the $\mathrm{F}_{1} \mathrm{~F}_{\mathrm{o}}$ ATP synthase), which is the complex primarily known for its role as an ion channel that couples proton flux from the inter-membrane space into the matrix with ATP synthesis through interactions with the $F_{1}$ subunit of the ATP synthase complex (Jonckheere et al., 2012). Tight regulation of ATP synthesis, and prevention of ATP consumption during dormancy associated with diapause or anoxia is clearly important (StPierre et al., 2000). Making inferences on the possible functional implications of these sequence changes is difficult due to a lack of detailed information on the crystal structure of the $F_{o}$ complex (DeLeon-Rangel et al., 2013). The role of the rather 
TABLE 2 | A. limnaeus mitochondrial feature table.

\begin{tabular}{|c|c|c|c|c|c|c|c|c|}
\hline Gene/element & Strand & Start position & Stop position & Size (bp) & Start codon & Stop codon & $3^{\prime a}$ & $\mathrm{TM}^{\mathrm{b}}$ \\
\hline tRNA-Phe & $\mathrm{H}$ & 1 & 69 & 69 & - & - & 0 & - \\
\hline 12S rRNA & $\mathrm{H}$ & 70 & 1015 & 946 & - & - & 0 & - \\
\hline tRNA-Val & $\mathrm{H}$ & 1016 & 1084 & 69 & - & - & 0 & - \\
\hline 16S rRNA & $\mathrm{H}$ & 1085 & 2718 & 1634 & - & - & 0 & - \\
\hline tRNA-Leu2 & $\mathrm{H}$ & 2719 & 2791 & 73 & - & - & 0 & - \\
\hline tRNA-Leu2 & $\mathrm{H}$ & 5740 & 5812 & 73 & - & - & 0 & - \\
\hline D-loop 2 & - & 5813 & 8175 & 2363 & - & - & 0 & - \\
\hline ND1 & $\mathrm{H}$ & 8176 & 9123 & 948 & GTG & TAA & 2 & 8 \\
\hline tRNA-Ile & $\mathrm{H}$ & 9126 & 9193 & 68 & - & - & -1 & - \\
\hline tRNA-GIn & $L$ & 9193 & 9263 & 71 & - & - & -1 & - \\
\hline tRNA-Ala & L & 10458 & 10526 & 69 & - & - & 1 & - \\
\hline tRNA-Asn & L & 10528 & 10600 & 73 & - & - & 0 & - \\
\hline $\mathrm{O}_{\mathrm{L}}$ & - & 10601 & 10636 & 36 & - & - & 0 & - \\
\hline tRNA-Cys & L & 10637 & 10693 & 57 & - & - & 2 & - \\
\hline tRNA-Tyr & $\mathrm{L}$ & 10696 & 10763 & 68 & - & - & 1 & - \\
\hline $\mathrm{COI}$ & $\mathrm{H}$ & 10765 & 12327 & 1563 & ACG & TAA & 2 & 12 \\
\hline tRNA-Ser2 & $\mathrm{L}$ & 12330 & 12399 & 70 & - & - & 2 & - \\
\hline tRNA-Asp & $\mathrm{H}$ & 12402 & 12472 & 71 & - & - & 2 & - \\
\hline COII & $\mathrm{H}$ & 12475 & 13165 & 691 & GTG & $\mathrm{T}-$ & 0 & 3 \\
\hline tRNA-Lys & $\mathrm{H}$ & 13166 & 13231 & 66 & - & - & 2 & - \\
\hline ATPase-8 & $\mathrm{H}$ & 13234 & 13401 & 168 & $A C G$ & TAA & -16 & 1 \\
\hline tRNA-His & $\mathrm{H}$ & 17037 & 17105 & 69 & - & - & 2 & - \\
\hline tRNA-Ser & $\mathrm{H}$ & 17108 & 17171 & 62 & - & - & 3 & - \\
\hline tRNA-Leu & $\mathrm{H}$ & 17175 & 17246 & 72 & - & - & 2 & - \\
\hline ND5 & $\mathrm{H}$ & 17249 & 19111 & 1863 & ATA & TAA & -4 & 16 \\
\hline ND6 & $L$ & 19108 & 19575 & 468 & GTG & TAA & 54 & 4 \\
\hline tRNA-Glu & $\mathrm{L}$ & 19630 & 19698 & 69 & - & - & 4 & - \\
\hline Cyt-b & $\mathrm{H}$ & 19703 & 20838 & 1136 & ATG & TA- & 0 & 8 \\
\hline tRNA-Thr & $\mathrm{H}$ & 20839 & 20908 & 70 & - & - & -1 & - \\
\hline tRNA-Pro & $\mathrm{L}$ & 20908 & 20980 & 73 & - & - & 0 & - \\
\hline
\end{tabular}

a Number of bases until the start of the next gene or feature.

${ }^{b}$ Total number of transmembrane domains in protein coding genes as identified by TOPOS.

long extension of the C-terminus in ATPase-6 is intriguing and potentially offers the possibility of altered interactions with other subunits of the complex or with proteins in the intermembrane space.

Because complexes I and V both contain several essential and accessory subunits encoded by the nucleus, it will be interesting to see if these other subunits also contain structural changes that are divergent from other fish species. Additionally, confirmation of these complex I and complex V subunit features in other populations of A. limnaeus and exploration of the functional consequences of these features may be a fruitful area for future studies. 


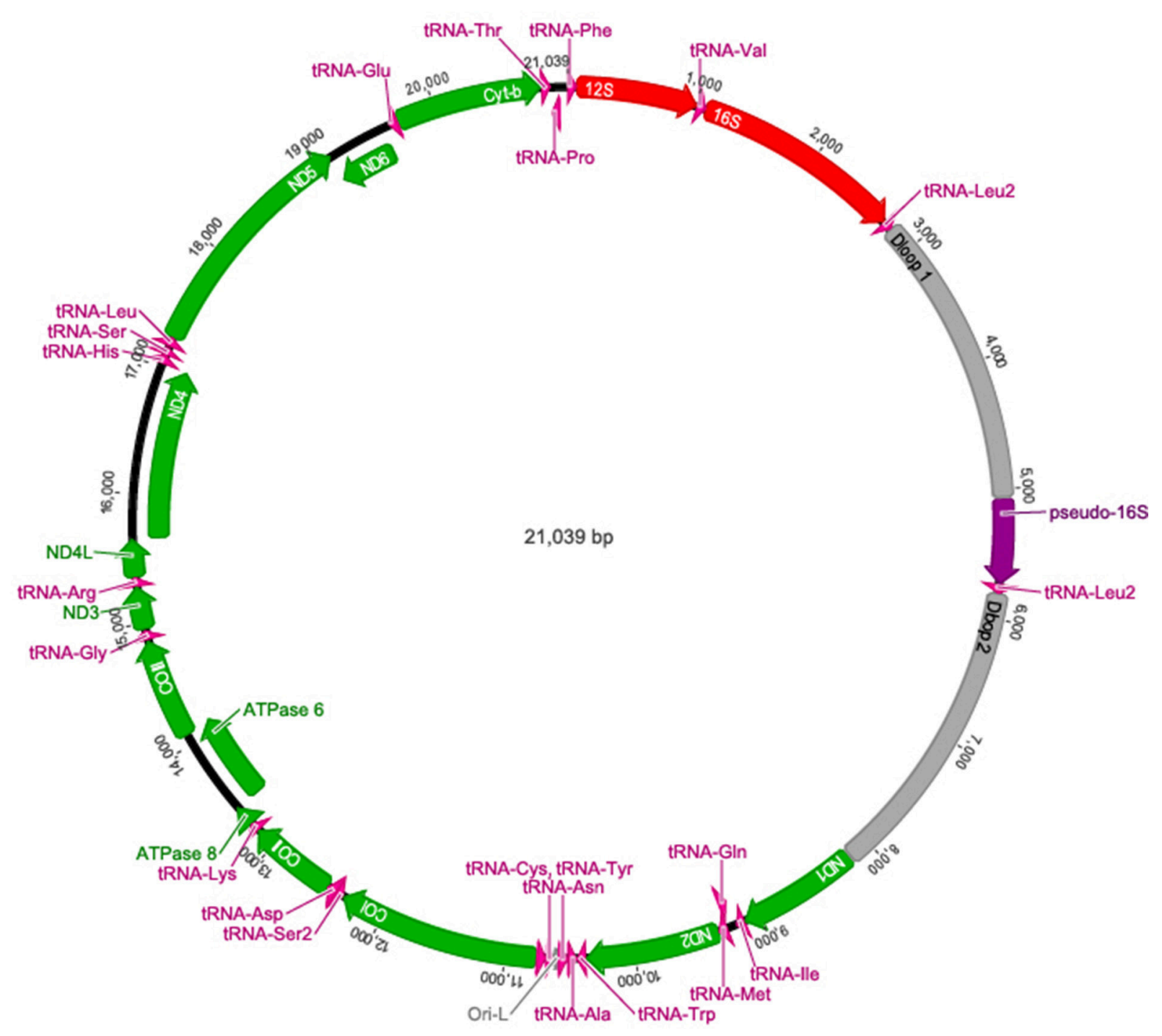

FIGURE 1 | The complete annotated mtgenome of $\boldsymbol{A}$. limnaeus. Protein coding genes are noted in green, tRNAs in pink, D-loops and the origin of light strand replication (abbreviated Ori-L) are in gray, rRNA in red, and the pseudo-16S rRNA in purple.

\section{Non-coding and Pseudo16s Region}

Sequence alignment of the two A. limnaeus D-loops (Alim-Dloop 1 and Alim-Dloop 2) identified a 1497 bp region with $100 \%$ pairwise identity with the remaining $3^{\prime}$ sections appearing to be evolving independently (Figure 5). Both Alim-D-loop 1 and Alim-D-loop 2 contain a high proportion of AT repeats, the most frequent of which is the motif "TAA," significantly clustered in the unshared portion of D-loop sequences (Figure S3). After alignment of D-loops from several species, two putative CSBs were identified in A. limnaeus (CSB-1 and CSB-2), and these CSBs were discovered in both Alim-D-loop 1 and Alim-D-loop 2 based on the conserved motif previously identified by Broughton et al. (2001) (Figure 6). Aside from the three aplocheloid species (Nothobranchius furzeri, Kryptolebias marmoratus and A. limnaeus) a single D-loop is found between tRNA-Phe and
tRNA-Pro, suggesting that this may be the ancestral positioning of the D-loop. In A. limnaeus, the non-coding region between tRNA-Phe and tRNA-Pro has been reduced to $59 \mathrm{bp}$ (referred to as pseudoDloop from this point forward), several hundred bps smaller than the other species examined. NCBI blast of this short region did not yield significant results, nor did the sequence have high identity to any other region in the A. limnaeus mtgenome. Although sequence and length of the D-loop region can be highly variable between species, possibly due to relaxed selection (Lee et al., 1995), the presence of large D-loop translocations or duplications appears to be uncommon in fishes. Duplicate D-loops have been previously described in snakes (Kumazawa et al., 1996, 1998; Dubey et al., 2012), birds (Abbott et al., 2005; Morris-Pocock et al., 2010), and fish (Lee et al., 2001; Li et al., 2015), but the physiological implications of having repositioned 


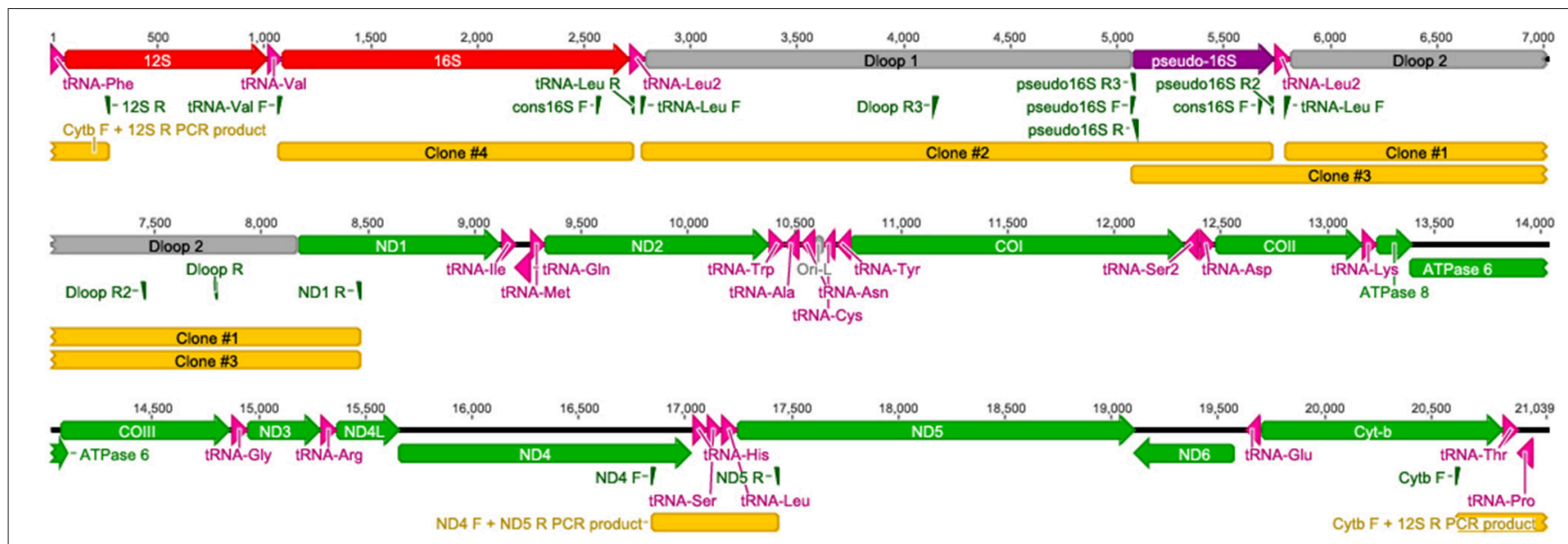

FIGURE 2 | Primer binding sites for targeted resequencing of the $\boldsymbol{A}$. limnaeus mtgenome. Specific primers were used to resequence parts of the $A$. limnaeus mtgenome. Longer fragments were cloned into vectors for sequencing.

TABLE 3 | Nucleotide polymorphisms detected in the A. limnaeus mtgenome using the Geneious variant caller.

\begin{tabular}{|c|c|c|c|c|c|c|}
\hline Gene & Position(s) & Polymorphism Type ${ }^{a}$ & Variant Frequency & Length $^{b}$ & Change(s) & Coverage \\
\hline ND4L & 15,751 & SNP (transversion) & $25.0 \%$ & $1 \mathrm{bp}$ & $\mathrm{T} \rightarrow \mathrm{A}$ & $9616 X$ \\
\hline $16 S$ & 1584; 1587; 1588; 1591 & MNV (transitions) & $25.1 \%-25.7 \%$ & 8 bp & $\mathrm{G} \rightarrow \mathrm{A} ; \mathrm{G} \rightarrow \mathrm{A} ; \mathrm{T} \rightarrow \mathrm{C} ; \mathrm{T} \rightarrow \mathrm{C}$ & $7222 X-7507 X$ \\
\hline
\end{tabular}

Variants were called with a threshold of $\geq 10 \%$ occurrence in the Illumina reads.

a SNP, single nucleotide polymorphism; MNV, multinucleotide polymorphism.

${ }^{b}$ Total length in bp that the polymorphism spans over the reference sequence.

and/or duplicated D-loops are unclear. In snakes, there is evidence that both regions are able to function in replication and transcription processes (Jiang et al., 2007). Similar to the D-loop duplication found in K. marmoratus (Lee et al., 2001), the snake duplicated D-loop regions flank both the $12 \mathrm{~S}$ and $16 \mathrm{~S}$ rRNAs. Jiang et al. (2007) proposed that having dual regulatory regions might allow for differential regulation of mitochondrial rRNA and mRNA, but this hypothesis has yet to be tested. In typical mammalian mitochondria, different transcriptional binding sites allow for differential transcription of rRNA and mRNAs, with one polycistronic molecule transcribing almost the entire $\mathrm{H}$ strand, and the other stopping after transcribing through the 12S and 16S rRNAs (Fernández-Silva et al., 2003). FernándezSilva et al. (2003) showed that the incomplete polycistronic RNA containing the $16 \mathrm{~S}$ and $12 \mathrm{~S}$ rRNA is transcribed $\sim 20$ times more frequently than the polycistronic RNA covering nearly the entire $\mathrm{H}$ strand, suggesting that rRNA abundance is an important factor in mitochondrial function. Interestingly, $\mathrm{H}$-strand transcription starting from the repositioned D-loop in A. limnaeus would cause the rRNAs to be transcribed near the end of the polycistronic molecule. This implies that either a new transcriptional start site has evolved upstream of the rRNAs, or that all of the H-strand protein coding and tRNA genes would be transcribed along with rRNAs after every round of transcription. Coordinated expression of the entire $\mathrm{H}$-strand may be advantageous to $A$. limnaeus by allowing for rapid and simultaneous expression, or depression, of tRNA, rRNA, and mRNA. The presence of CSB2, thought to be important in mitochondrial RNA transcription stabilization (Xu and Clayton, 1995; Fernández-Silva et al., 2003; Pham et al., 2006), in both D-loops suggests that H-strand RNA polymerase binding sites may also be duplicated, perhaps allowing for increased transcription rates of the $\mathrm{H}$-strand. Loss of a canonical D-loop between tRNA-Phe and tRNA-Pro has been previously described in the tongue sole, Cynoglossus semilaevis, whereby the D-loop occurs in between the ND1 and tRNA-Gln genes. Thus, it appears fish mitochondrial genomes are able to tolerate diverse translocations of the D-loop while still retaining function.

Occurring between D-loop 1 and D-loop 2 is a region with partial homology to the $16 \mathrm{~S}$ rRNA, including a 178 bp $(95.2 \%$ identity) and $431 \mathrm{bp}$ ( $88.5 \%$ identity) region, collectively referred to as pseudo-16S (Figure 7). The occurrence of the region between $C y t b$ and the 12S rRNA and the occurrence of both the $16 \mathrm{~S}$ and pseudo-16S regions were confirmed in multiple $A$. limnaeus adult individuals (Figure S4). The putative origin of light-strand replication (Ori-L) is a 36 bp region found between tRNA-Asn and tRNA-Cys and is predicted to fold into a stable hairpin structure (Figure 8; Seutin et al., 1994). The Ori-L also contains the conserved motif $3^{\prime}$-GGCCG-5' near the $5^{\prime}$ end of the hairpin structure, a sequence thought to interact with replication enzymes to direct light-strand replication (Hixson et al., 1986; Hurst et al., 1999). 



FIGURE 3 | Alignments of $A$. limnaeus ND1, ND5, ND6, and ATPase-6 genes to other species. When compared to other species, there are apparent multinucleotide deletions in the $5^{\prime}$ region of $A$. limnaeus ND1 (27 bp) and ND6 (54 bp). ND5 appears to have a multinucleotide insertion near the $5^{\prime}$ end when compared to multispecies consensus (33 bps), while ATPase- 6 is extended by several nucleotides at the $5^{\prime}$ end (6 bp) and $3^{\prime}$ end (34 bp). 


\section{Mitochondrial tRNAs}

Although nearly all tRNAs were identified and folded into predicted structures (Figure 9), neither MitoAnnotator nor MITOS annotation pipelines were able to predict tRNA-Ser (anticodon $\mathrm{AGN}$ ) in A. limnaeus. Mapping of the N. furzeri tRNA-Ser sequence to the assembled $A$. limnaeus mtgenome identified a putitative A. limnaeus tRNA-Ser (51.5\% pairwise identity). The putative A. limnaeus tRNA-Ser has the potential to fold into a cloverleaf structure, as predicted using Geneious. Similar to the previous report for the A. charrua mtgenome, the A. limnaeus tRNA-Cys is predicted to be the same length as that of $A$. charrua at $57 \mathrm{bp}$ and to lack the D-arm (Figure 9). This feature of tRNA-Cys missing the D-arm [tRNA-Cys $(-D)$ ] found in the two South American annual killifishes is not found in

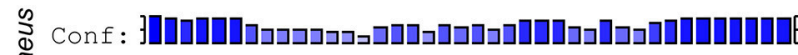

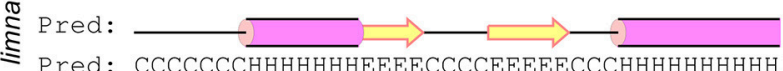 $\varangle$ AA: MASNPPPNLGALSLVLVAGCGCGILACYGVGELSLVLFLI 20 30 40

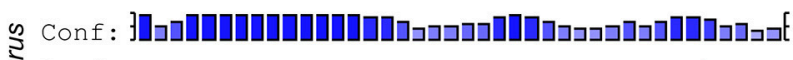 $\underset{\sim}{\mathbb{D}}$ Pred: - \\ œ Pred: CHHHHHHHHHHHHHHHHHCCCCCCCCCCCEEEEEEECCCC AA: MMLYIVF ILSVIFVMGFVGFSSKP SP IYGGLGLIVSGGVG $\begin{array}{llll}10 & 20 & 30 & 40\end{array}$ \\ Legend:

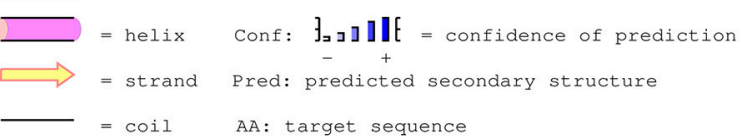

FIGURE 4 | Comparison of PSIPRED secondary structure results for $A$. limnaeus and bovine ND6. The secondary structure predictions of ND6 in the two species suggests that the $A$. limnaeus protein may be lacking a complete first helix when compared to bovine. any of the species examined here, all of which carry a complete tRNA-Cys [tRNA-Cys(+D)] of typical tRNA length. The $A$. limnaeus mtgenome also contains a duplicated tRNA-Leu2. Although uncommon, duplicated mitochondrial tRNAs have been previously reported, including the Cyprinodontiform

\begin{tabular}{|c|c|}
\hline $\begin{array}{l}\text { CSB-1 } \\
\text { Consensus } \\
\text { Identity }\end{array}$ & 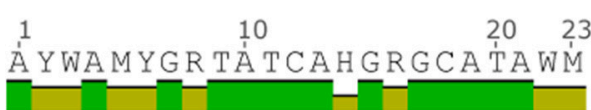 \\
\hline $\begin{array}{l}\text { A. limnaeus } \\
\text { A. panchax } \\
\text { F. diaphanus } \\
\text { F. heteroclitus } \\
\text { G. affnis } \\
\text { K. marmoratus } \\
X . \text { hellerii } \\
X . \text { maculatus } \\
\text { O. latipes }\end{array}$ & 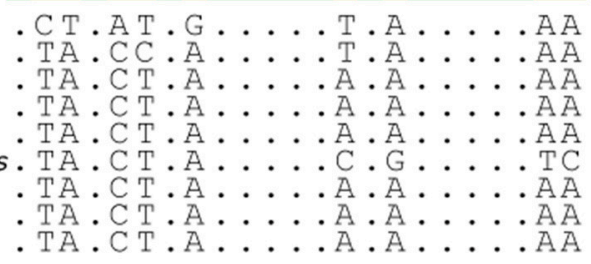 \\
\hline
\end{tabular}

CSB-2

Consensus Identity
A. limnaeus
A. charrua
A. panchax
C. rubrofluviatilis
F. diaphanus
F. grandis
F. heteroclitus
F. olivaceus
G. affnis
K. marmoratus
N. furzeri
$X$. hellerii
X. eiseni
X. maculatus
O. latipes

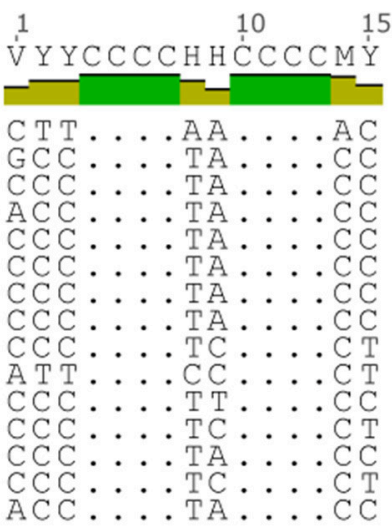

FIGURE 6 | Consensus motifs of CSB-1 (top) and CSB-2 (bottom) found in the D-loops of species used in this study. CSBs were found by searching the mtgenomes using conserved motifs based on previous work by Broughton et al. (2001).

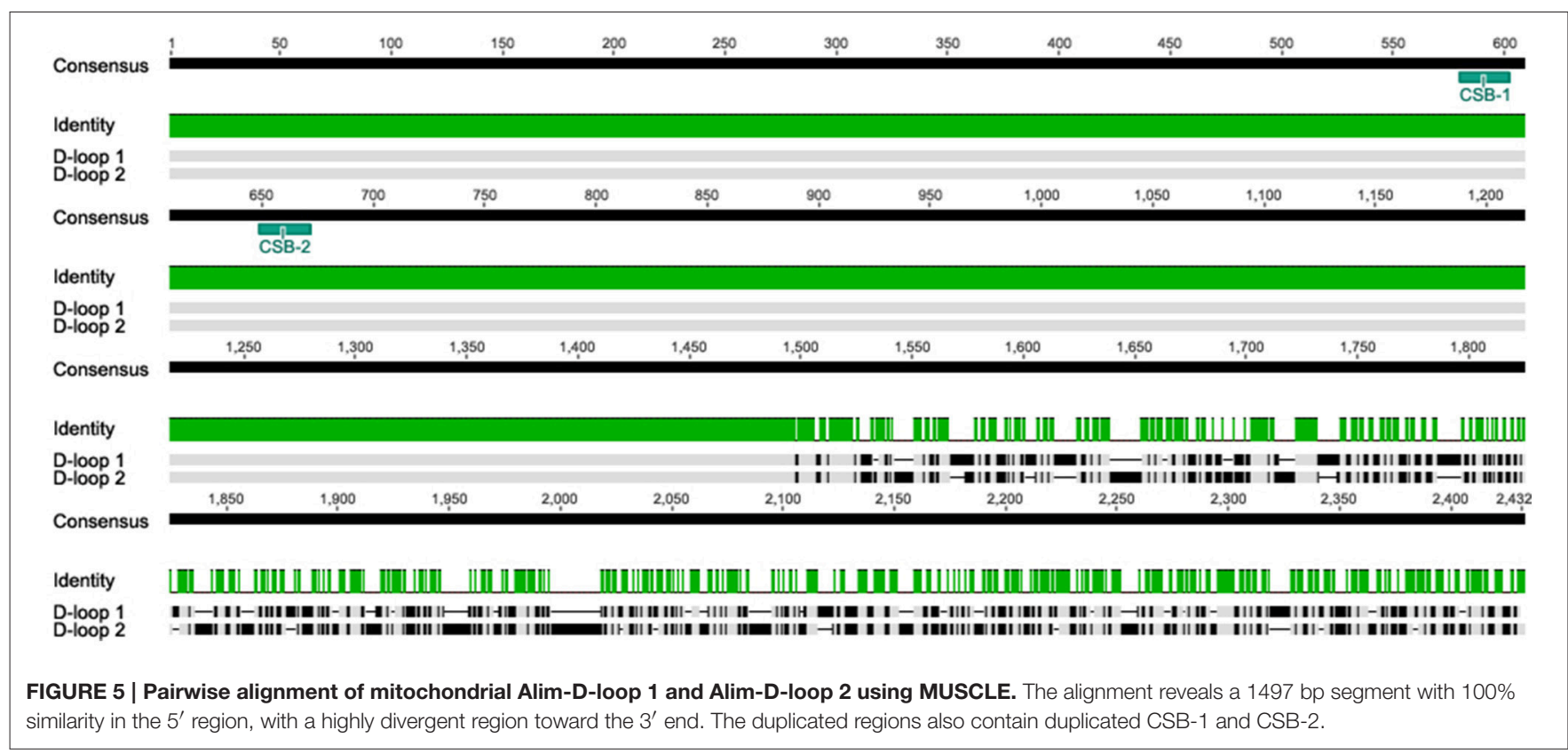




Identity ${ }_{16 \mathrm{~S}}^{\text {Pseudo16S }}$

FIGURE 7 | Pairwise MUSCLE alignment of part of 16S rRNA to the pseudo-16S rRNA region in the $\boldsymbol{A}$. limnaeus mtgenome. The pseudo16S region is located between Alim-D-loop 1 and Alim-D-loop 2. The alignment reveals regions of high similarity between the 16S rRNA and the pseudo-16S. Relative to the reference mtgenome sequence, the pseudo16S region shown here is from positions 4814 to 5812 and the $16 \mathrm{~S}$ region is from 2227 to 2791.



Xenoteca eiseni (duplicated tRNA-Met; Setiamarga et al., 2008). Initially, the $N$. furzeri mtgenome was thought to contain a duplicated tRNA-Glu but more recently this putative tRNA was suggested to be a pseudogene (Hartmann et al., 2011; Tatarenkov et al., 2015).

\section{RNAseq Mapping Predicts Mitochondrial Transcript Polyadenylation Sites}

We found a total of 13 regions with polyadenylation signals supported by RNAseq mapping (Figure 10, Supplemental Data Sheet 1). Overall, the mtgenome had an average of $72,697 \mathrm{X}$ (s.d. $=100,465.3$ ) with a minimum coverage of $181 \mathrm{X}$ and maximum of 909,375X (Figure S5). These data also confirmed the completion of stop codons by posttranscriptional polyadenylation for ND2, COII, ND3, and $C y t-b$ genes as predicted by MitoAnnotator (Table 2). In contrast to a similar analysis performed on the Atlantic Cod (Gadus morhua) that utilized deep RNA sequencing (Coucheron et al., 2011), we found that ATPase- 8 and ATPase-6 do not share a single bicistronic transcript but instead the polyadenylation site occurs downstream following COIII. Additionally, the Atlantic Cod ND5 was reported to contain a stop codon immediately at the end of the coding region, while the A. limnaeus ND5 transcript is not polyadenylated until after the antisense ND6 and tRNA-Glu are transcribed, 592 bases downstream of the end of ND5. This long $3^{\prime}$ trailer following ND5 is more similar in length to the trailer found in humans than in the Atlantic Cod (Temperley et al., 2010). Similar to previous reports for the Atlantic Cod and humans, we found evidence for both mitochondrial rRNAs being polyadenylated (Dubin et al., 1982; Bakke and Johansen, 2002). Surprisingly, we observed a strong signal for polyadenylation of the presumed ancestral D-loop region (pseudoDloop) between tRNA-Pro and tRNA-Phe. However, nucleotide BLAST searches of this region did not yield homology to any known sequences in the nucleotide database and did not have significant similarity to any other regions in the A. limnaeus mtgenome. We also observed a clear polyadenylation signal at the $3^{\prime}$ end of the pseudo16S, suggesting that the $3^{\prime}$ end of the pseudo16S is still processed during mitochondrial transcript maturation.

\section{Phylogenetics of the Cyprinodontiformes Using mtDNA}

The use of mtDNA for phylogenetic inference has been a common practice for several decades. Although more recently the validity of such inferences that rely only on a single molecule with very important physiological roles has come into question (Ballard and Whitlock, 2004), phylogenetic inference based on mtDNA is still commonly used for species for which nuclear genome evidence is sparse. Use of all coding and tRNA sequences of mtgenomes has been shown to improve bootstrap support in teleost molecular phylogenies, and thus may provide improved phylogenetic inferences (Miya and Nishida, 2000). ML phylogenetic reconstruction using the concatenated supergenes revealed a similar topology to that found by Tatarenkov et al. (2015). As expected, Aplocheilus panchax, N. furzeri, K. marmoratus, A. charrua, and A. limnaeus form a single clade 


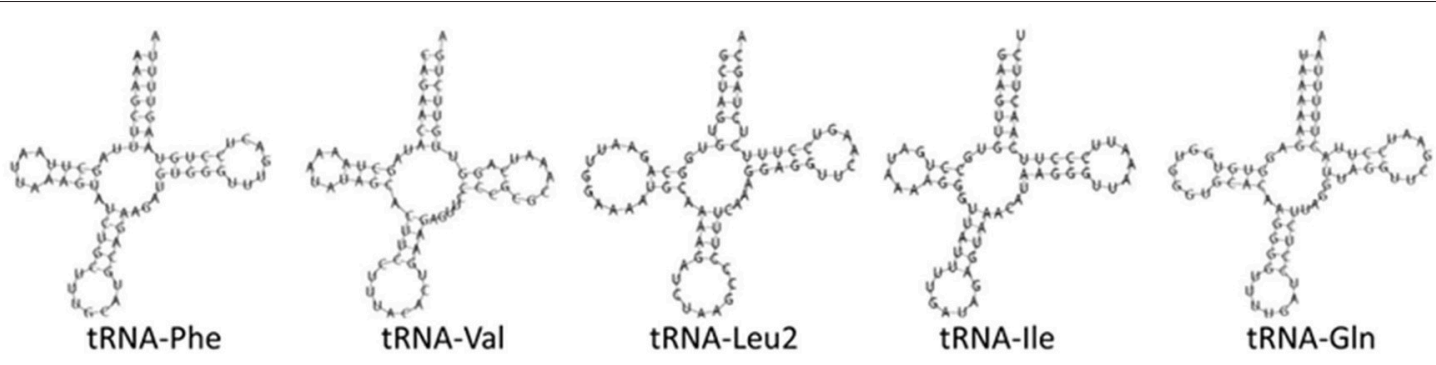

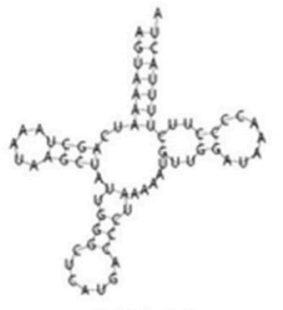

tRNA-Met

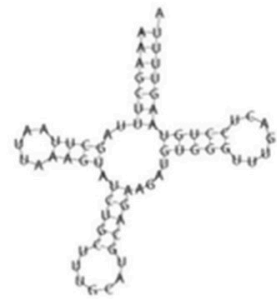

tRNA-Ala

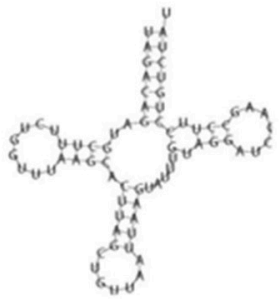

tRNA-Asn

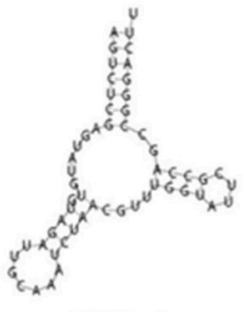

tRNA-Cys
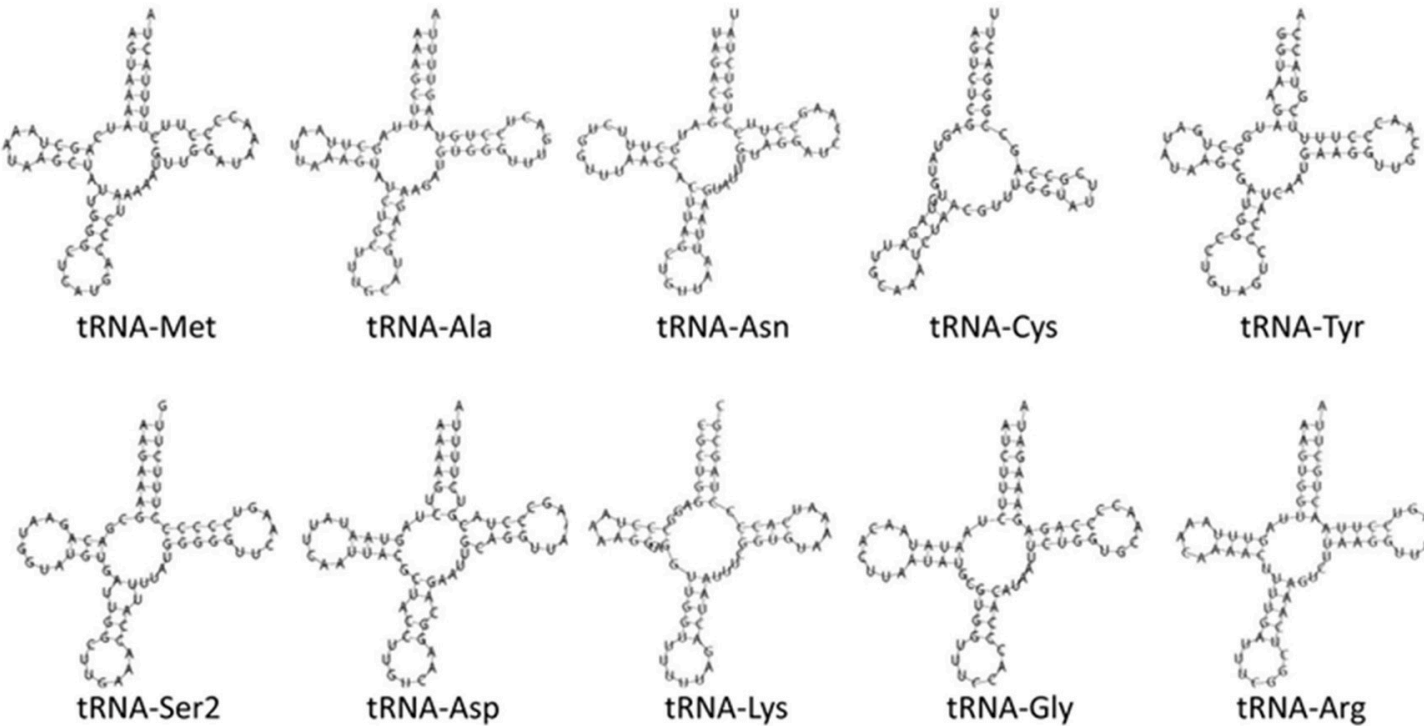

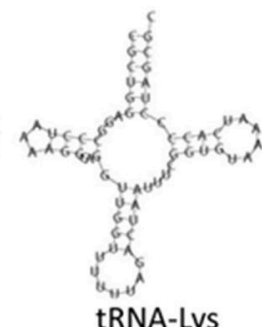

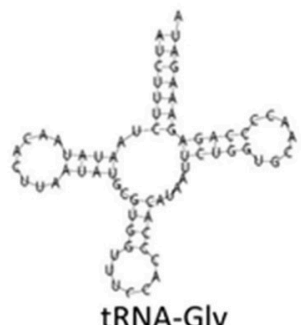

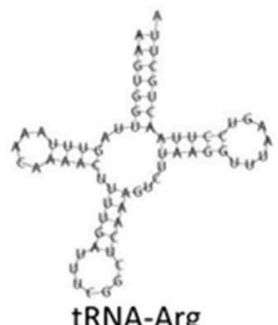

tRNA-Arg

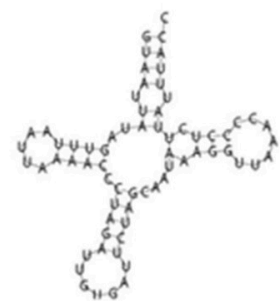

tRNA-His

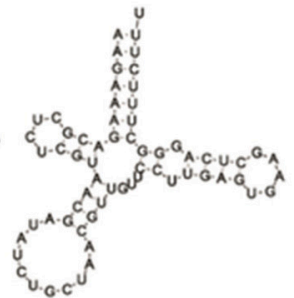

tRNA-Ser



tRNA-Leu

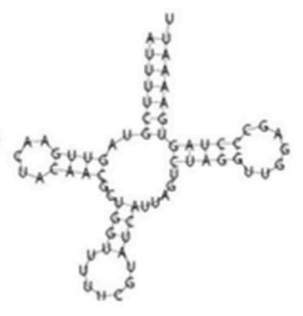

tRNA-Glu

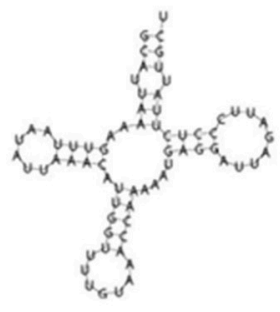

tRNA-Thr

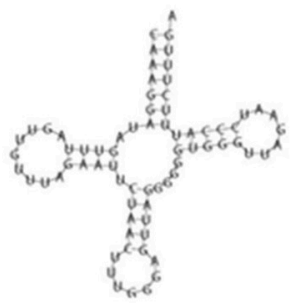

tRNA-Pro

FIGURE 9 | Predicted secondary structures of identified mitochondrial tRNAs in the $\boldsymbol{A}$. limnaeus mtgenome. The A. limnaeus tRNA-Ser was identified by mapping the N. furzeri tRNA-Ser to the A. limnaeus mtgenome and was folded using Geneious. All other tRNAs were folded by MITOS.

representative of the Aplocheiloidei superfamily, with the other Cyprinodontiformes forming the Cyprinodontoidei superfamily clade (Figure 11). Within the Aplocheiloidei superfamily, the topology is in general agreement with the multigene phylogenetic tree proposed by Pohl et al. (2015) with a notable exception that within the Family Rivulidae, Austrolebias is sister to 


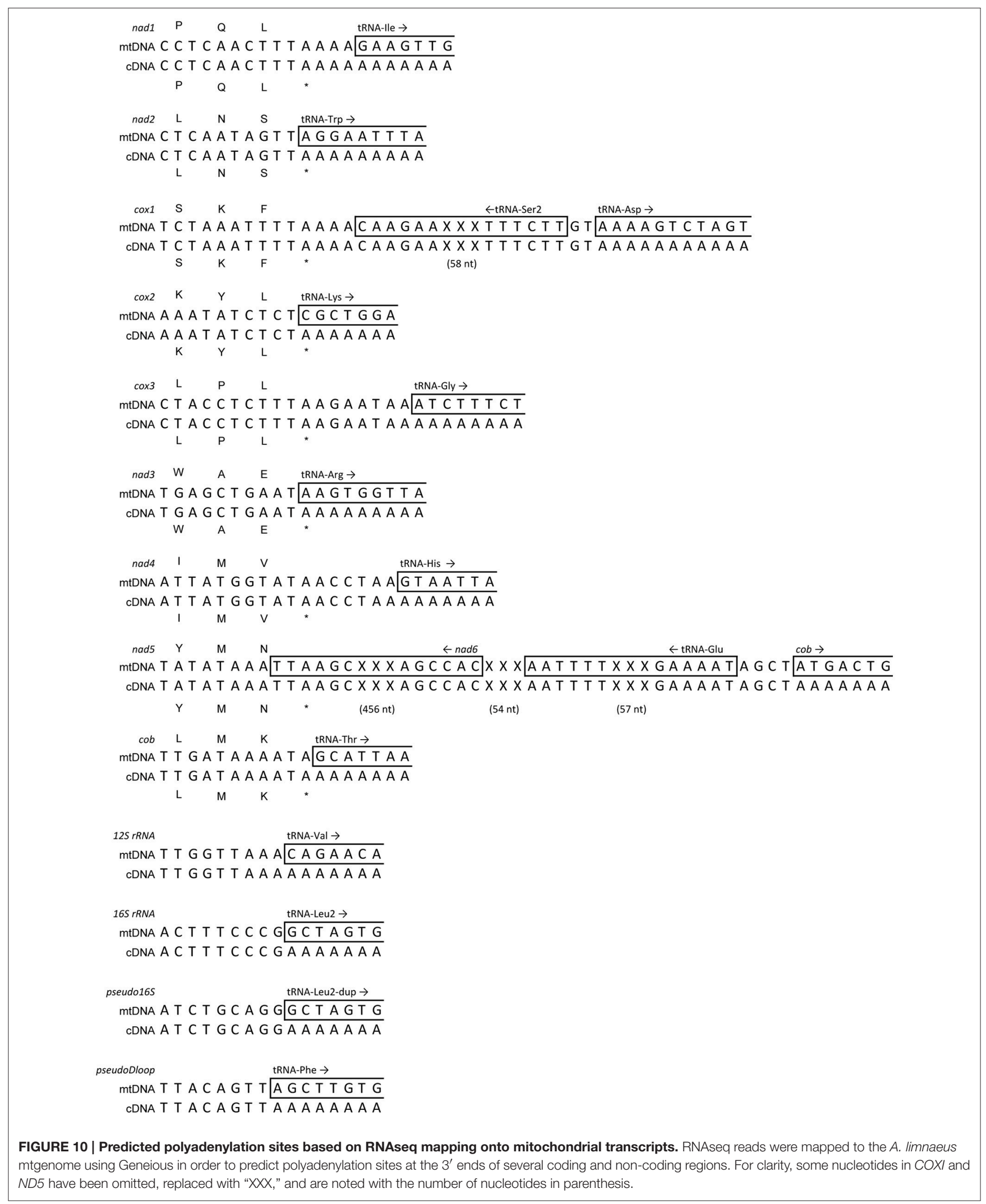




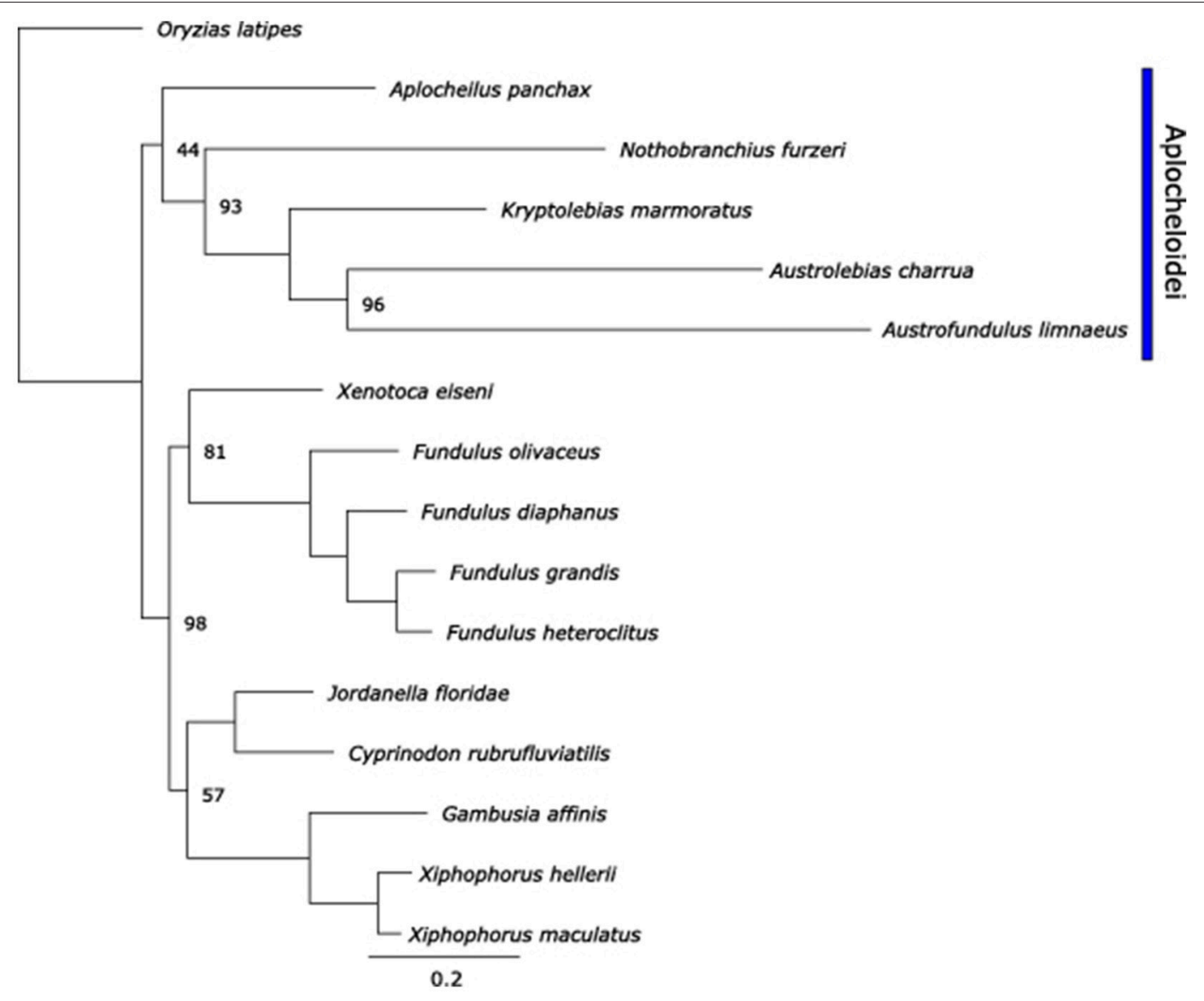

FIGURE 11 | Maximum-likelihood phylogenetic tree of species used in this paper using RAxML. Node bootstrap values are $100 \%$ unless indicated otherwise. Scale bar is nucleotide substitutions per site.

Kryptolebias in the multigene tree, while the mitochondriaonly tree identifies Austrolebias as sister to Austrofundulus. If the multigene species tree is accepted to also represent the phylogenetic history of each species' mitochondria, this would imply that either (1) the tRNA-Cys $(-D)$ was independently derived in A. limnaeus and A. charrua, or (2) the last common ancestor for $K$. marmoratus, A. limnaeus, and A. charrua was heteroplasmic for tRNA-Cys $(+D /-D)$ and later the tRNACys(-D) genotype became fixed in the two annual killifish species. If the mtDNA-only species tree is accepted, the most parsimonious hypothesis would be that tRNA-Cys(-D) first appeared in the last common ancestor for A. limnaeus and $A$. charrua. Additional mitochondrial sequences from species in the Family Rivulidae will prove useful for determining when tRNA-Cys $(-D)$ emerged and how common the feature may be.

\section{mtDNA Copy Number Dynamics and CS Activity During Normoxia or Anoxia}

We observed amplification efficiencies in the range of 91.194.9\% for all qPCR assays. Relative mtDNA copy number did not change significantly in WS 36, 40, or 42 embryos in response to exposure to anoxia or during normoxic recovery (One-way ANOVA, $P=0.749$ for WS $36, P=0.741$ for WS 40 , and $P=$
0.75 for WS42; Figure 12). Across normoxic post-diapause II development, the mean relative mtDNA copy number decreased by about $40 \%$ in WS 40 embryos when compared to DII, but this trend was not statistically significant (One-way ANOVA, $P=0.1288$ ). Because the amplification-based method of qPCR is only able to detect $\geq 2$ fold differences, a more sensitive approach to measuring relative mtDNA may be able to determine if this trend does indeed occur during post-diapause II development.

Exposure to anoxia and up to $24 \mathrm{~h}$ of aerobic recovery from anoxia did not result in significant changes in CS activity when compared to $t=0$ for any of the embryonic stages investigated. These data indicate an overall stabilization of existing CS activity in embryos exposed to anoxia for the three stages tested. In WS 36 embryos, there was an overall statistical significance in CS activity means (one-way ANOVA, $P=0.0028$ ). Tukey's MCT identified significant differences between $t=0$ and $48 \mathrm{~h}$ normoxia $(P<0.001)$, and between $24 \mathrm{~h}$ anoxia and $48 \mathrm{~h}$ normoxia $(P<0.001)$, but no differences were found when $24 \mathrm{~h}$ recovery or $24 \mathrm{~h}$ normoxia when compared to other treatments within the stage. Thus, in embryos treated at WS 36 , the $24 \mathrm{~h}$ anoxia treatment is more similar to $t=0$ than to $48 \mathrm{~h}$ normoxia and suggests a slight developmental delay in increased CS activity due to anoxia exposure that is no 


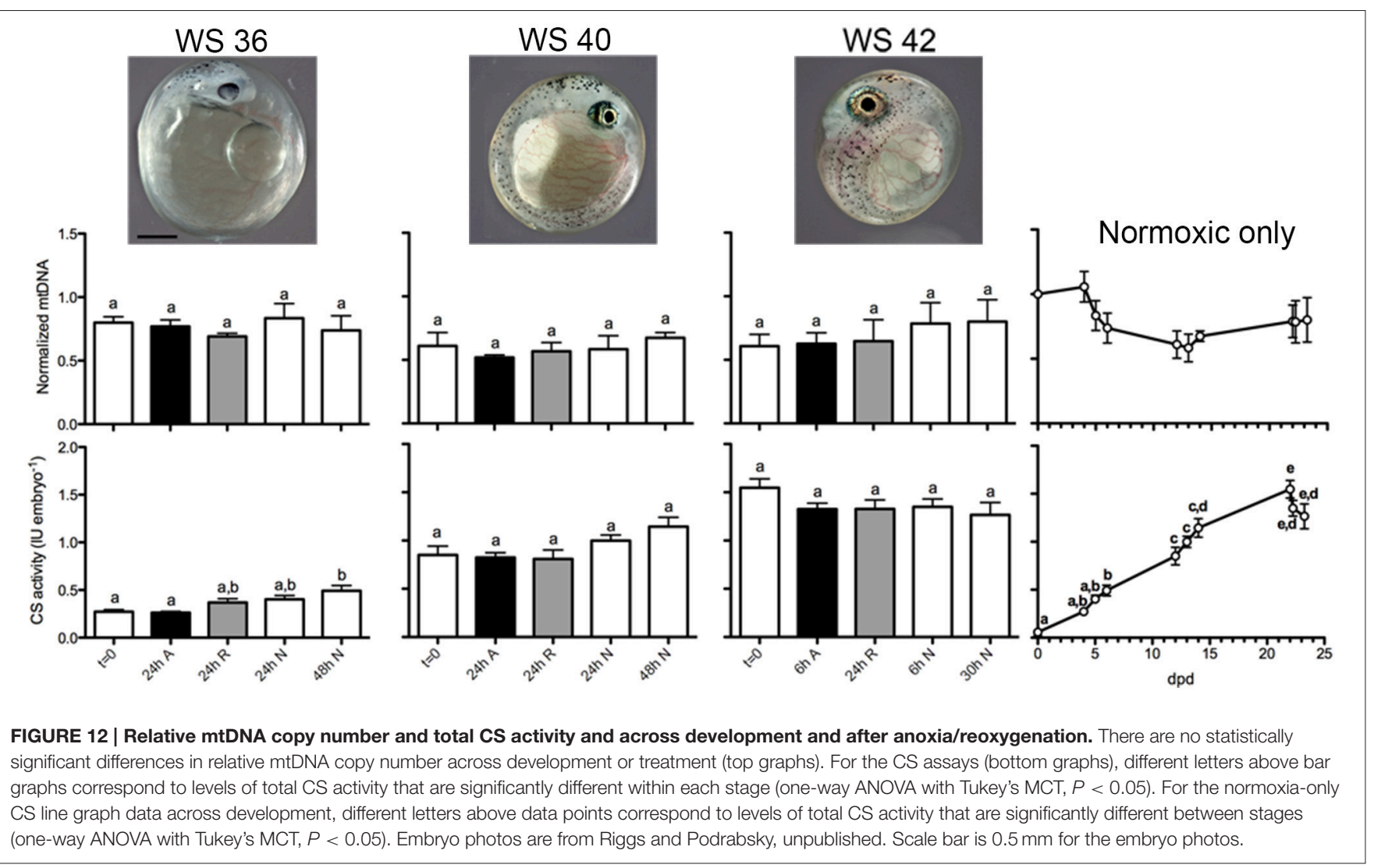

longer apparent after $24 \mathrm{~h}$ recovery. In the WS 40 embryos, there were no statistical differences between means following Tukey's MCT, although there was an overall trend for statistical significance within the stage (one-way ANOVA, $P=0.045$ ). In the WS 42 embryos the complex pattern of CS activity associated with entrance into DIII makes the comparison of the anoxia treatments difficult to interpret, and no significant differences were found (one way ANOVA, $P=0.31$ ). In contrast to mtDNA copy number across normoxic development, total embryonic CS activity increased linearly starting from DII until $22 \mathrm{dpd}$ at an average rate of $0.0705 \mathrm{IU}$ embryo ${ }^{-1}$ day $^{-1}\left(R^{2}=0.988\right.$, Figure 12). This linear trend closely resembles a previous report of total CS activity in developing post-DII A. limnaeus embryos by Chennault and Podrabsky (2010). In addition, the increase in total CS activity during post-DII development coincides with a previously reported increase in overall respiratory complex II, IV, and V activity of post-DII A. limnaeus embryos (Duerr and Podrabsky, 2010). Following a peak in CS activity at $22 \mathrm{dpd}$, total CS activity starts to decline in embryos reared in normoxic conditions, presumably as embryos begin to depress aerobic metabolism and enter into DIII (Podrabsky and Hand, 1999). Overall, the changes in CS activity across normoxic post-diapause development were significant (one-way ANOVA, $P<0.0001$ ) with individual differences across development following Tukey's MCT shown in Figure 12.

Taken together, these data suggest that there is no direct association between relative mtDNA copy number and aerobic metabolism across normoxic post-DII development in $A$. limnaeus. This trend is similar to zebrafish embryos, whereby the mtDNA/gDNA ratio does not change significantly from $6 \mathrm{~h}$ post-fertilization (shield stage) until the end of embryonic development, but the overall rate of aerobic metabolism increases linearly over this same period (Stackley et al., 2011; Artuso et al., 2012). These data imply that as cells replicate during fish embryonic development, on average the number of mtDNA copies per cell remains consistent and does not coincide with the increase in overall aerobic metabolism in a whole embryo. Additionally, these data support the more general hypothesis that total mitochondrial respiration is not regulated at the level of mtDNA copy number (Attardi and Schatz, 1988).

Vertebrate mitochondria are generally highly responsive to changes in oxygen availability (Bickler and Buck, 2007). In mammals, anoxia-sensitive mammalian cells substantially reduce mitochondrial volume and mtDNA copy number when exposed to a hypoxic environment, a result likely achieved through mitophagy (Zhang et al., 2008; Youle and Van Der Bliek, 2012). Reoxygenation after ischemia is typically accompanied by biogenesis of mitochondria, as demonstrated by significant increases in mtDNA content, total cytochrome $c$ oxidase Subunit IV (COIV) protein, total CS activity, and total mitochondria number after $24 \mathrm{~h}$ of reoxygenation (Yin et al., 2008). It is likely that reactive oxygen species (ROS) mediated signaling associated with reperfusion initiates this response (Lee and Wei, 2005; Li et al., 2012). Whether this biogenesis following 
reoxgenation is adaptive is uncertain, although it has been suggested to counteract mitochondrial dysfunction by the production of new mitochondria (Rasbach and Schnellmann, 2007; Chen et al., 2011). Nonetheless, these studies suggest that mammalian mitochondria respond dynamically to low oxygen and ischemia/reoxygenation conditions. This response is clearly not shared by embryos of A. limnaeus in response to anoxia, as demonstrated by unchanged relative mtDNA content and total CS activity following anoxia or reoxygenation (Figure 12). It should be noted that active development of WS 40 and 42 embryos is absolutely dependent on aerobic respiration (Podrabsky and Hand, 1999). Further, all the postdiapause II stages investigated in this study are comprised of several tissues that are typically oxygen-sensitive, such as a brain and heart, and yet there is no significant change in relative mtDNA content or CS activity in response to anoxia or reoxygenation. Our data suggest that anoxia-tolerant organisms such as A. limnaeus do not utilize mitophagy during periods of acute anoxia and do not respond with mitochondrial biogenesis following reoxygenation. Although ROS levels have not yet been measured in A. limnaeus embryos following anoxia treatment, it is possible that mitochondrial biogenesis does not occur following reoxygenation because cellular ROS-mediated signaling levels do not become elevated. This is supported by evidence from studies in adult tissues from another anoxia-tolerant vertebrate, the freshwater turtle, where ROS levels are not significantly elevated following anoxia/reoxygenation (Milton et al., 2007). Additionally, there is no evidence for lipid peroxidation during anoxia/reoxygenation in the turtle, further supporting the hypothesis that ROS is effectively controlled in anoxia-tolerant species through unclear mechanisms that may involve antioxidants (Willmore and Storey, 1997; Lutz and Milton, 2004). It would be worthwhile to measure ROS levels in A. limnaeus embryos following anoxia/reoxygenation to determine if indeed ROS levels are suppressed, or if there are alternative mechanisms that suppress mitochondrial biogenesis in this species. Additionally, it would be of interest to determine if there is actually mitochondrial turnover (simultaneous biogenesis and degradation) occurring following oxygen insult, whereby the net change in total mitochondria would be near zero, as these data are insufficient to distinguish between mitochondrial turnover and overall stability.

\section{AUTHOR CONTRIBUTIONS}

JW prepared the genomic DNA for sequencing and assembled/annotated the $A$. limnaeus mtgenome with the appropriate software. JW performed the phylogenetic analyses, primer design, PCR for Sanger sequencing, nucleotide alignments, qPCR assays, CS assays, statistical analysis, and wrote the manuscript. FH assisted with validation of $\mathrm{qPCR}$ products, preparation and sequencing of clones, performed CS assays, and provided manuscript edits. JEP conceived of the study along with JW and provided manuscript edits and statistical advice.

\section{FUNDING}

This work was funded by a National Science Foundation (NSF) grant (IOS-1354549) to JEP and research stipend support to $\mathrm{FH}$ from the Portland State University Louis Stokes Alliance for Minority Participation (NSF, HRD-140465).

\section{ACKNOWLEDGMENTS}

We would like to thank Drs. Dee Denver and Kim Brown for use of lab equipment, lab space, and computer hardware. We thank Matthew Dalrymple for help with scripting. We also would like to thank Dr. Suzanne Estes for advice with analysis of the mtgenome. Computationally analyses were performed with support from the PSU Research Computing service.

\section{SUPPLEMENTARY MATERIAL}

The Supplementary Material for this article can be found online at: http://journal.frontiersin.org/article/10.3389/fphys. 2016.00379

Figure S1 | Overall nucleotide composition of $A$. limnaeus mitochondrial coding genes and RNAs. The nucleotide compositions of the coding genes are separated by codon position. Pos1, codon position 1; Pos2, codon position 2; Pos3, codon position 3; 4fold pos3, codon position 3 that can have any 4 nucleotides in position while still coding for the same amino acid.

Figure S2 | GC and AT skewness across A. limnaeus mtgenome coding regions. The $A$. limnaeus mtgenome tends to have bias toward $C$ and $T$ nucleotides in all coding genes except for ND6, which has a bias toward $G$ and $T$. These data do not include stop codons.

Figure S3 | RepFind analysis of Alim-D-loop 1 (top panel) and Alim-D-loop 2 (bottom panel) repetitive motifs. Both D-loops have a high proportion of repeats high in T and A toward the $3^{\prime}$ end. The RepFind $P$-value indicates the probability of finding the cluster of the specific type of repeats by chance alone.

Figure S4 | Verification of $A$. limnaeus mtgenome regions across individuals and tissue types using PCR. The Cytb F-12S R primer set amplifies the region that contains the canonical D-loop in most other species, thus confirming the loss of the ancestral D-loop in multiple $A$. limnaeus individuals and tissue types. The Cons 16S- F-tRNA-Leu R primer set amplifies regions using primers that are conserved between the 16S rRNA and pseudo-16S, demonstrating the truncated length associated with the pseudo 16S. Abbreviations: Liv, liver; Ov, ovary; WM, white muscle.

Figure S5 | RNAseq coverage of the A. limnaeus mtgenome. The coverage ranges from a minimum of $181 X$ to a maximum of $909,375 X$ and covers the reference sequence completely. Reads were mapped using Geneious as described in the main text.

Table S1 | Primer names and sequences used to verify regions of the $A$. limnaeus mtgenome. These primers were used to generate PCR fragments for cloning into the pGEM-T vector, for sequencing the vectors, or both.

Table S2 | Primers used to generate and sequence clones for assembly of the $\boldsymbol{A}$. limnaeus $\mathrm{mtgenome.} \mathrm{PCR} \mathrm{fragments} \mathrm{were} \mathrm{generated} \mathrm{using} \mathrm{the} \mathrm{listed}$ primer pairs for each clone and were inserted into the pGEM-T vector. Clones were sequenced using the listed primers.

Table S3 | Illumina reads used for assembly and mapping of the $A$. limnaeus mitochondrial genome. Reads were trimmed using Trimmomatic prior to sequence assembly using MitoBIM. SD, standard deviation.

Table S4 | Primers specific to mitochondrial NADH dehydrogenase subunit 4 (ND4) or nuclear insulin-like growth factor-1 receptor (IGFR1) used for measurement of relative mtDNA content. Primer sequences were generated using the IDT PrimerQuest tool. 
Table S5 | Top five most used codons in the A. limnaeus, $A$. charrua, $N$. furzeri, $\boldsymbol{K}$. marmoratus, and $\boldsymbol{A}$. panchax mtgenomes. Codon usage was determined using CAlcal. Top codons that are shared by all five species are noted in bold.

\section{REFERENCES}

Abbott, C. L., Double, M. C., Trueman, J. W., Robinson, A., and Cockburn, A. (2005). An unusual source of apparent mitochondrial heteroplasmy: duplicate mitochondrial control regions in Thalassarche albatrosses. Mol. Ecol. 14, 3605-3613. doi: 10.1111/j.1365-294X.2005.02672.x

Artuso, L., Romano, A., Verri, T., Domenichini, A., Argenton, F., Santorelli, F. M., et al. (2012). Mitochondrial DNA metabolism in early development of zebrafish (Danio rerio). Biochim. Biophys. Acta 1817, 1002-1011. doi: 10.1016/j.bbabio.2012.03.019

Attardi, G., and Schatz, G. (1988). Biogenesis of mitochondria. Annu. Rev. Cell Biol. 4, 289-331. doi: 10.1146/annurev.cb.04.110188.001445

Bakke, I., and Johansen, S. (2002). Characterization of mitochondrial ribosomal RNA genes in gadiformes: sequence variations, secondary structural features, and phylogenetic implications. Mol. Phylogenet. Evol. 25, 87-100. doi: 10.1016/S1055-7903(02)00220-8

Ballard, J. W. O., and Whitlock, M. C. (2004). The incomplete natural history of mitochondria. Mol. Ecol. 13, 729-744. doi: 10.1046/j.1365-294X.2003. 02063.x

Bernt, M., Donath, A., Jühling, F., Externbrink, F., Florentz, C., Fritzsch, G., et al. (2013). MITOS: improved de novo metazoan mitochondrial genome annotation. Mol. Phylogenet. Evol. 69, 313-319. doi: 10.1016/j.ympev.2012.08.023

Betley, J. N., Frith, M. C., Graber, J. H., Choo, S., and Deshler, J. O. (2002). A ubiquitous and conserved signal for RNA localization in chordates. Curr. Biol. 12, 1756-1761. doi: 10.1016/S0960-9822(02)01220-4

Bickler, P. E., and Buck, L. T. (2007). Hypoxia tolerance in reptiles, amphibians, and fishes: life with variable oxygen availability. Аnnu. Rev. Physiol. 69, 145-170. doi: 10.1146/annurev.physiol.69.031905.162529

Bolger, A. M., Lohse, M., and Usadel, B. (2014). Trimmomatic: a flexible trimmer for Illumina sequence data. Bioinformatics 30, 2114-2120. doi: 10.1093/bioinformatics/btu170

Bratic, A., and Larsson, N.-G. R. (2013). The role of mitochondria in aging. J. Clin. Invest. 123, 951-957. doi: 10.1172/JCI64125

Broughton, R. E., Milam, J. E., and Roe, B. A. (2001). The complete sequence of the zebrafish (Danio rerio) mitochondrial genome and evolutionary patterns in vertebrate mitochondrial DNA. Genome Res. 11, 1958-1967. doi: $10.1101 /$ gr.156801

Buchan, D. W., Minneci, F., Nugent, T. C., Bryson, K., and Jones, D. T. (2013). Scalable web services for the PSIPRED protein analysis workbench. Nucleic Acids Res. 41, W349-W357. doi: 10.1093/nar/gkt381

Castresana, J. (2000). Selection of conserved blocks from multiple alignments for their use in phylogenetic analysis. Mol. Biol. Evol. 17, 540-552. doi: 10.1093/oxfordjournals.molbev.a026334

Chen, S.-D., Yang, D.-I., Lin, T.-K., Shaw, F.-Z., Liou, C.-W., and Chuang, Y.C. (2011). Roles of oxidative stress, apoptosis, PGC-1CE \pm and mitochondrial biogenesis in cerebral ischemia. Int. J. Mol. Sci. 12, 7199-7215. doi: 10.3390/ijms12107199

Chennault, T., and Podrabsky, J. E. (2010). Aerobic and anaerobic capacities differ in embryos of the annual killifish Austrofundulus limnaeus that develop on alternate developmental trajectories. J. Exp. Zool. A Ecol. Genet. Physiol. 313A, 587-596. doi: 10.1002/jez.632

Coucheron, D. H., Nymark, M., Breines, R., Karlsen, B. O., Andreassen, M., Jørgensen, T. E., et al. (2011). Characterization of mitochondrial mRNAs in codfish reveals unique features compared to mammals. Curr. Genet. 57, 213-222. doi: 10.1007/s00294-011-0338-2

Darriba, D., Taboada, G. L., Doallo, R., and Posada, D. (2012). jModelTest 2: more models, new heuristics and parallel computing. Nat. Methods 9, 772-772. doi: 10.1038/nmeth. 2109

DeLeon-Rangel, J., Ishmukhametov, R. R., Jiang, W., Fillingame, R. H., and Vik, S. B. (2013). Interactions between subunits $\mathrm{a}$ and $\mathrm{b}$ in the rotary

\section{Supplemental Data Sheet 1 |RNAseq mapping support for} polyadenylation sites in Excel spreadsheet format. $A 1, A 2$, and $A 3$ refer to the first, second, and third sites that mapped as non-reference adenosine.
ATP synthase as determined by cross-linking. FEBS Lett. 587, 892-897. doi: 10.1016/j.febslet.2013.02.012

Dubey, B., Meganathan, P., and Haque, I. (2012). Complete mitochondrial genome sequence from an endangered Indian snake, Python molurus molurus (Serpentes, Pythonidae). Mol. Biol. Rep. 39, 7403-7412. doi: 10.1007/s11033012-1572-5

Dubin, D. T., Montoya, J., Timko, K. D., and Attardi, G. (1982). Sequence analysis and precise mapping of the $3^{\prime}$ ends of HeLa cell mitochondrial ribosomal RNAs. J. Mol. Biol. 157, 1-19. doi: 10.1016/0022-2836(82)90510-1

Duerr, J. M., and Podrabsky, J. E. (2010). Mitochondrial physiology of diapausing and developing embryos of the annual killifish Austrofundulus limnaeus: implications for extreme anoxia tolerance. J. Comp. Physiol. B 180, 991-1003. doi: 10.1007/s00360-010-0478-6

Edgar, R. C. (2004). MUSCLE: multiple sequence alignment with high accuracy and high throughput. Nucleic Acids Res. 32, 1792-1797. doi: 10.1093/nar/gkh340

Fernández-Silva, P., Enriquez, J. A., and Montoya, J. (2003). Replication and transcription of mammalian mitochondrial DNA. Exp. Physiol. 88, 41-56. doi: 10.1113/eph8802514

Gnerre, S., MacCallum, I., Przybylski, D., Ribeiro, F. J., Burton, J. N., Walker, B. J., et al. (2011). High-quality draft assemblies of mammalian genomes from massively parallel sequence data. Proc. Natl. Acad. Sci. U.S.A. 108, 1513-1518. doi: 10.1073/pnas. 1017351108

Gutiérrez, V., Rego, N., Naya, H., and García, G. (2015). First complete mitochondrial genome of the South American annual fish Austrolebias charrua (Cyprinodontiformes: Rivulidae): peculiar features among cyprinodontiforms mitogenomes. BMC Genomics 16:879. doi: 10.1186/s12864-015-2090-3

Hahn, C., Bachmann, L., and Chevreux, B. (2013). Reconstructing mitochondrial genomes directly from genomic next-generation sequencing reads-a baiting and iterative mapping approach. Nucleic Acids Res. 41:e129. doi: 10.1093/nar/ gkt371

Hand, S. C., and Menze, M. A. (2008). Mitochondria in energy-limited states: mechanisms that blunt the signaling of cell death. J. Exp. Biol. 211, 1829-1840. doi: $10.1242 / \mathrm{jeb} .000299$

Hartmann, N., Reichwald, K., Wittig, I., Dröse, S., Schmeisser, S., Lück, C., et al. (2011). Mitochondrial DNA copy number and function decrease with age in the short-lived fish Nothobranchius furzeri. Aging Cell 10, 824-831. doi: 10.1111/j.1474-9726.2011.00723.x

Hirst, J. (2013). Mitochondrial complex I. Annu. Rev. Biochem. 82, 551-575. doi: 10.1146/annurev-biochem-070511-103700

Hixson, J., Wong, T., and Clayton, D. A. (1986). Both the conserved stem-loop and divergent $5^{\prime}$-flanking sequences are required for initiation at the human mitochondrial origin of light-strand DNA replication. J. Biol. Chem. 261, 2384-2390.

Hrbek, T., Taphorn, D. C., and Thomerson, J. E. (2005). Molecular phylogeny of Austrofundulus Myers (Cyprinodontiformes: Rivulidae), with revision of the genus and the description of four new species. Zootaxa 825, 1-39.

Hurst, C. D., Bartlett, S. E., Davidson, W. S., and Bruce, I. J. (1999). The complete mitochondrial DNA sequence of the Atlantic salmon, Salmo salar. Gene 239, 237-242. doi: 10.1016/S0378-1119(99)00425-4

Iwasaki, W., Fukunaga, T., Isagozawa, R., Yamada, K., Maeda, Y., Satoh, T. P., et al. (2013). MitoFish and MitoAnnotator: a mitochondrial genome database of fish with an accurate and automatic annotation pipeline. Mol. Biol. Evol. 30, 2531-2540. doi: 10.1093/molbev/mst141

Jiang, Z. J., Castoe, T. A., Austin, C. C., Burbrink, F. T., Herron, M. D., McGuire, J. A., et al. (2007). Comparative mitochondrial genomics of snakes: extraordinary substitution rate dynamics and functionality of the duplicate control region. BMC Evol. Biol. 7:123. doi: 10.1186/1471-2148-7-123

Johnston, M. V., Trescher, W. H., Ishida, A., and Nakajima, W. (2001). Neurobiology of hypoxic-ischemic injury in the developing brain. Pediatr. Res. 49, 735-741. doi: 10.1203/00006450-200106000-00003 
Jonckheere, A. I., Smeitink, J. A., and Rodenburg, R. J. (2012). Mitochondrial ATP synthase: architecture, function and pathology. J. Inherit. Metab. Dis. 35, 211-225. doi: 10.1007/s10545-011-9382-9

Jones, D. T. (1999). Protein secondary structure prediction based on position-specific scoring matrices. J. Mol. Biol. 292, 195-202. doi: 10.1006/jmbi.1999.3091

Kearse, M., Moir, R., Wilson, A., Stones-Havas, S., Cheung, M., Sturrock, S., et al. (2012). Geneious Basic: an integrated and extendable desktop software platform for the organization and analysis of sequence data. Bioinformatics 28, 1647-1649. doi: 10.1093/bioinformatics/bts199

Kowald, A., and Kirkwood, T. B. (2014). Transcription could be the key to the selection advantage of mitochondrial deletion mutants in aging. Proc. Natl. Acad. Sci. U.S.A. 111, 2972-2977. doi: 10.1073/pnas.1314970111

Kumazawa, Y., and Nishida, M. (1993). Sequence evolution of mitochondrial tRNA genes and deep-branch animal phylogenetics. J. Mol. Evol. 37, 380-398. doi: 10.1007/BF00178868

Kumazawa, Y., Ota, H., Nishida, M., and Ozawa, T. (1996). Gene rearrangements in snake mitochondrial genomes: highly concerted evolution of control-regionlike sequences duplicated and inserted into a tRNA gene cluster. Mol. Biol. Evol. 13, 1242-1254. doi: 10.1093/oxfordjournals.molbev.a025690

Kumazawa, Y., Ota, H., Nishida, M., and Ozawa, T. (1998). The complete nucleotide sequence of a snake (Dinodon semicarinatus) mitochondrial genome with two identical control regions. Genetics 150, 313-329.

Lee, H.-C., and Wei, Y.-H. (2005). Mitochondrial biogenesis and mitochondrial DNA maintenance of mammalian cells under oxidative stress. Int. J. Biochem. Cell Biol. 37, 822-834. doi: 10.1016/j.biocel.2004.09.010

Lee, J.-S., Miya, M., Lee, Y.-S., Kim, C. G., Park, E.-H., Aoki, Y., et al. (2001). The complete DNA sequence of the mitochondrial genome of the self-fertilizing fish Rivulus marmoratus (Cyprinodontiformes, Rivulidae) and the first description of duplication of a control region in fish. Gene 280, 1-7. doi: 10.1016/S03781119(01)00765-X

Lee, W.-J., Conroy, J., Howell, W. H., and Kocher, T. D. (1995). Structure and evolution of teleost mitochondrial control regions. J. Mol. Evol. 41, 54-66. doi: 10.1007/BF00174041

Levraut, J., Iwase, H., Shao, Z. H., Vanden Hoek, T. L., and Schumacker, P. T. (2003). Cell death during ischemia: relationship to mitochondrial depolarization and ROS generation. Am. J. Physiol. Heart Circ. Physiol. 284, H549-H558. doi: 10.1152/ajpheart.00708.2002

Li, D.-H., Shi, W., Munroe, T. A., Gong, L., and Kong, X.-Y. (2015). Concerted evolution of duplicate control regions in the mitochondria of species of the flatfish family Bothidae (Teleostei: Pleuronectiformes). PLoS ONE 10:e134580. doi: 10.1371/journal.pone.0134580

Li, J., Ma, X., Yu, W., Lou, Z., Mu, D., Wang, Y., et al. (2012). Reperfusion promotes mitochondrial dysfunction following focal cerebral ischemia in rats. PLoS ONE 7:e46498. doi: 10.1371/journal.pone.0046498

Lutz, P. L., and Milton, S. L. (2004). Negotiating brain anoxia survival in the turtle. J. Exp. Biol. 207, 3141-3147. doi: 10.1242/jeb.01056

Marková, S., Filipi, K., Searle, J. B., and Kotlík, P. (2015). Mapping $3^{\prime}$ transcript ends in the bank vole (Clethrionomys glareolus) mitochondrial genome with RNA-Seq. BMC Genomics 16:870. doi: 10.1186/s12864-0152103-2

Mathews, D. H., Disney, M. D., Childs, J. L., Schroeder, S. J., Zuker, M., and Turner, D. H. (2004). Incorporating chemical modification constraints into a dynamic programming algorithm for prediction of RNA secondary structure. Proc. Natl. Acad. Sci. U.S.A. 101, 7287-7292. doi: 10.1073/pnas.0401799101

Meller, C. L., and Podrabsky, J. E. (2013). Avoidance of apoptosis in embryonic cells of the annual killifish Austrofundulus limnaeus exposed to anoxia. PLoS ONE 8:e75837. doi: 10.1371/journal.pone.0075837

Milton, S. L., Nayak, G., Kesaraju, S., Kara, L., and Prentice, H. M. (2007). Suppression of reactive oxygen species production enhances neuronal survival in vitro and in vivo in the anoxia-tolerant turtle Trachemys scripta. J. Neurochem. 101, 993-1001. doi: 10.1111/j.1471-4159.2007.04466.x

Miya, M., and Nishida, M. (2000). Use of mitogenomic information in teleostean molecular phylogenetics: a tree-based exploration under the maximumparsimony optimality criterion. Mol. Phylogenet. Evol. 17, 437-455. doi: 10.1006/mpev.2000.0839

Miya, M., Takeshima, H., Endo, H., Ishiguro, N. B., Inoue, J. G., Mukai, T., et al. (2003). Major patterns of higher teleostean phylogenies: a new perspective based on 100 complete mitochondrial DNA sequences. Mol. Phylogenet. Evol. 26, 121-138. doi: 10.1016/S1055-7903(02)00332-9

Morris-Pocock, J. A., Taylor, S. A., Birt, T. P., and Friesen, V. L. (2010). Concerted evolution of duplicated mitochondrial control regions in three related seabird species. BMC Evol. Biol. 10:14. doi: 10.1186/1471-2148-10-14

Pfaffl, M. (2001). A new mathematical model for relative quantification in real-time RT-PCR. Nucleic Acids Res. 29:e45. doi: 10.1093/nar/29.9.e45

Pham, X. H., Farge, G. R., Shi, Y., Gaspari, M., Gustafsson, C. M., and Falkenberg, M. (2006). Conserved sequence box II directs transcription termination and primer formation in mitochondria. J. Biol. Chem. 281, 24647-24652. doi: 10.1074/jbc.M602429200

Podrabsky, J. E. (1999). Husbandry of the annual killifish Austrofundulus limnaeus with special emphasis on the collection and rearing of embryos. Environ. Biol. Fish. 54, 421-431.

Podrabsky, J. E., Carpenter, J. F., and Hand, S. C. (2001). Survival of water stress in annual fish embryos: dehydration avoidance and egg envelope amyloid fibers. Am. J. Physiol. 280, R123-R131.

Podrabsky, J. E., and Hand, S. C. (1999). The bioenergetics of embryonic diapause in an annual killifish, Austrofundulus limnaeus. J. Exp. Biol. 202, 2567-2580.

Podrabsky, J. E., and Hand, S. C. (2000). Depression of protein synthesis during diapause in embryos of the annual killifish Austrofundulus limnaeus. Physiol. Biochem. Zool. 73, 799-808. doi: 10.1086/318106

Podrabsky, J. E., Hrbek, T., and Hand, S. C. (1998). Physical and chemical characteristics of ephemeral pond habitats in the Maracaibo basin and Llanos region of Venezuela. Hydrobiologia 362, 67-78. doi: 10.1023/A:1003168704178

Podrabsky, J. E., Lopez, J. P., Fan, T. W. M., Higashi, R., and Somero, G. N. (2007). Extreme anoxia tolerance in embryos of the annual killifish Austrofundulus limnaeus: insights from a metabolomics analysis. J. Exp. Biol. 210, 2253-2266. doi: 10.1242/jeb.005116

Podrabsky, J. E., Menze, M. A., and Hand, S. C. (2012a). Long-term survival of anoxia despite rapid ATP decline in embryos of the annual killifish Austrofundulus limnaeus. J. Exp. Zool. A Ecol. Genet. Physiol. 317, 524-532. doi: 10.1002/jez.1744

Podrabsky, J. E., Riggs, C. L., and Duerr, J. M. (2012b). "Anoxia tolerance during vertebrate development - insights from studies on the annual killifish Austrofundulus limnaeus," in Anoxia, ed P. Padilla (Rijeka: InTech), 3-24.

Podrabsky, J., Riggs, C., and Wagner, J. (2015). “Tolerance of environmental stress," in Annual Fishes. Life History Strategy, Diversity, and Evolution, eds N. Berois G. García and R. De Sá (Boca Raton, FL: CRC Press, Taylor \& Francis), 159-184.

Pohl, M., Milvertz, F. C., Meyer, A., and Vences, M. (2015). Multigene phylogeny of cyprinodontiform fishes suggests continental radiations and a rogue taxon position of Pantanodon. Vertebr. Zool. 65, 37-44.

Puigbò, P., Bravo, I. G., and Garcia-Vallve, S. (2008). CAIcal: a combined set of tools to assess codon usage adaptation. Biol. Direct 3:38. doi: 10.1186/17456150-3-38

Quinlan, C. L., Treberg, J. R., Perevoshchikova, I. V., Orr, A. L., and Brand, M. D. (2012). Native rates of superoxide production from multiple sites in isolated mitochondria measured using endogenous reporters. Free Radic. Biol. Med. 53, 1807-1817. doi: 10.1016/j.freeradbiomed.2012.08.015

Rasbach, K. A., and Schnellmann, R. G. (2007). Signaling of mitochondrial biogenesis following oxidant injury. J. Biol. Chem. 282, 2355-2362. doi: 10.1074/jbc.M608009200

Setiamarga, D. H., Miya, M., Yamanoue, Y., Mabuchi, K., Satoh, T. P., Inoue, J. G., et al. (2008). Interrelationships of Atherinomorpha (medakas, flyingfishes, killifishes, silversides, and their relatives): the first evidence based on whole mitogenome sequences. Mol. Phylogenet. Evol. 49, 598-605. doi: 10.1016/j.ympev.2008.08.008

Seutin, G., Lang, B. F., Mindell, D. P., and Morais, R. (1994). Evolution of the WANCY region in amniote mitochondrial DNA. Mol. Biol. Evol. 11, 329-340.

Stackley, K. D., Beeson, C. C., Rahn, J. J., and Chan, S. S. (2011). Bioenergetic profiling of zebrafish embryonic development. PLoS ONE 6:e25652. doi: 10.1371/journal.pone.0025652

Stamatakis, A. (2006). RAxML-VI-HPC: maximum likelihood-based phylogenetic analyses with thousands of taxa and mixed models. Bioinformatics 22, 2688-2690. doi: 10.1093/bioinformatics/btl446

Stowe, D. F., and Camara, A. K. (2009). Mitochondrial reactive oxygen species production in excitable cells: modulators of mitochondrial and cell function. Antioxid. Redox Signal. 11, 1373-1414. doi: 10.1089/ars.2008.2331 
St-Pierre, J., Brand, M. D., and Boutilier, R. G. (2000). Mitochondria as ATP consumers: cellular treason in anoxia. Proc. Natl. Acad. Sci. U.S.A. 97, 8670-8674. doi: 10.1073/pnas.140093597

Tatarenkov, A., Mesak, F., and Avise, J. C. (2015). Complete mitochondrial genome of a self-fertilizing fish Kryptolebias marmoratus (Cyprinodontiformes, Rivulidae) from Florida. Mitochondrial DNA. doi: 10.3109/19401736.2015.1115861. [Epub ahead of print].

Temperley, R. J., Wydro, M., Lightowlers, R. N., and Chrzanowska-Lightowlers, Z. M. (2010). Human mitochondrial mRNAs-like members of all families, similar but different. Biochim. Biophys. Acta 1797, 1081-1085. doi: 10.1016/j.bbabio.2010.02.036

Torres, J. J., and Somero, G. N. (1988). Metabolism, enzymic activities and cold adaptation in antarctic mesopelagic fishes. Mar. Biol. 98, 169-180. doi: 10.1007/BF00391192

Tsirigos, K. D., Peters, C., Shu, N., Käll, L., and Elofsson, A. (2015). The TOPCONS web server for consensus prediction of membrane protein topology and signal peptides. Nucleic acids Res. 41, W401-W407. doi: 10.1093/nar/ gkv485

UniProt, C. (2015). UniProt: a hub for protein information. Nucleic Acids Res. 43, D204-D212. doi: 10.1093/nar/gku989

Verma, S., Fedak, P. W. M., Weisel, R. D., Butany, J., Rao, V., Maitland, A., et al. (2002). Fundamentals of reperfusion injury for the clinical cardiologist. Circulation 105, 2332-2336. doi: 10.1161/01.CIR.0000016602.96 363.36

Vinothkumar, K. R., Zhu, J., and Hirst, J. (2014). Architecture of mammalian respiratory complex I. Nature 515, 80-84. doi: 10.1038/nature13686

Wagner, J. T., and Podrabsky, J. E. (2015). Gene expression patterns that support novel developmental stress buffering in embryos of the annual killifish Austrofundulus limnaeus. EvoDevo 6:2. doi: 10.1186/2041-9139-6-2

Whitehead, A. (2009). Comparative mitochondrial genomics within and among species of killifish. BMC Evol. Biol. 9:11. doi: 10.1186/1471-2148-9-11

Willmore, W., and Storey, K. (1997). Antioxidant systems and anoxia tolerance in a freshwater turtle Trachemys scripta elegans. Mol. Cell. Biochem. 170, 177-185. doi: 10.1023/A:1006817806010
Wourms, J. P. (1972a). Developmental biology of annual fishes I. Stages in the normal development of Austrofundulus myersi Dahl. J. Exp. Zool. 182, 143-168.

Wourms, J. P. (1972b). The developmental biology of annual fish II. Naturally occuring dispersion and reaggregation of blastomeres during the development of annual fish eggs. J. Exp. Zool. 182, 169-200.

Wourms, J. P. (1972c). The developmental biology of annual fishes III. Preembryonic and embryonic diapause of variable duration in the eggs of annual fishes. J. Exp. Zool. 182, 389-414.

$\mathrm{Xu}, \mathrm{B}$., and Clayton, D. A. (1995). A persistent RNA-DNA hybrid is formed during transcription at a phylogenetically conserved mitochondrial DNA sequence. Mol. Cell. Biol. 15, 580-589. doi: 10.1128/MCB.15.1.580

Yin, W., Signore, A. P., Iwai, M., Cao, G., Gao, Y., and Chen, J. (2008) Rapidly increased neuronal mitochondrial biogenesis after hypoxicischemic brain injury. Stroke 39, 3057-3063. doi: 10.1161/STROKEAHA.108. 520114

Youle, R. J., and Van Der Bliek, A. M. (2012). Mitochondrial fission, fusion, and stress. Science 337, 1062-1065. doi: 10.1126/science. 1219855

Zhang, H., Bosch-Marce, M., Shimoda, L. A., Tan, Y. S., Baek, J. H., Wesley, J. B., et al. (2008). Mitochondrial autophagy is an HIF-1-dependent adaptive metabolic response to hypoxia. J. Biol. Chem. 283, 10892-10903. doi: 10.1074/jbc.M800102200

Conflict of Interest Statement: The authors declare that the research was conducted in the absence of any commercial or financial relationships that could be construed as a potential conflict of interest.

Copyright (c) 2016 Wagner, Herrejon Chavez and Podrabsky. This is an openaccess article distributed under the terms of the Creative Commons Attribution License (CC BY). The use, distribution or reproduction in other forums is permitted, provided the original author(s) or licensor are credited and that the original publication in this journal is cited, in accordance with accepted academic practice. No use, distribution or reproduction is permitted which does not comply with these terms. 